\title{
Sensitivity of the Regional Climate in the Middle East and North Africa to Volcanic
}

\section{Perturbations}

Muhammad Mubashar Dogar ${ }^{1}$, Georgiy Stenchikov ${ }^{1}$, Sergey Osipov ${ }^{1}$, Bruce Wyman ${ }^{2}$, Ming Zhao $^{2}$

${ }^{1}$ King Abdullah University of Science and Technology (KAUST), Thuwal, Saudi Arabia ${ }^{2}$ NOAA Geophysical Fluid Dynamics Laboratory, Princeton, USA

\section{Corresponding Author}

Muhammad Mubashar Dogar

Email: muhammad.dogar@kaust.edu.sa

King Abdullah University of Science and Technology (KAUST), Thuwal, 23955-6900, Saudi Arabia

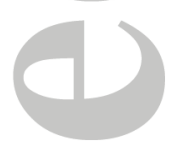

\section{Key Points:}

- MENA regional climate responds vigorously to strong equatorial volcanic eruptions

- The circulation changes due to forced positive phase of NAO cause most of the cooling in winter

- Volcanic radiative cooling and associated weakening of ISM cause drying and southward shift of ITCZ in summer

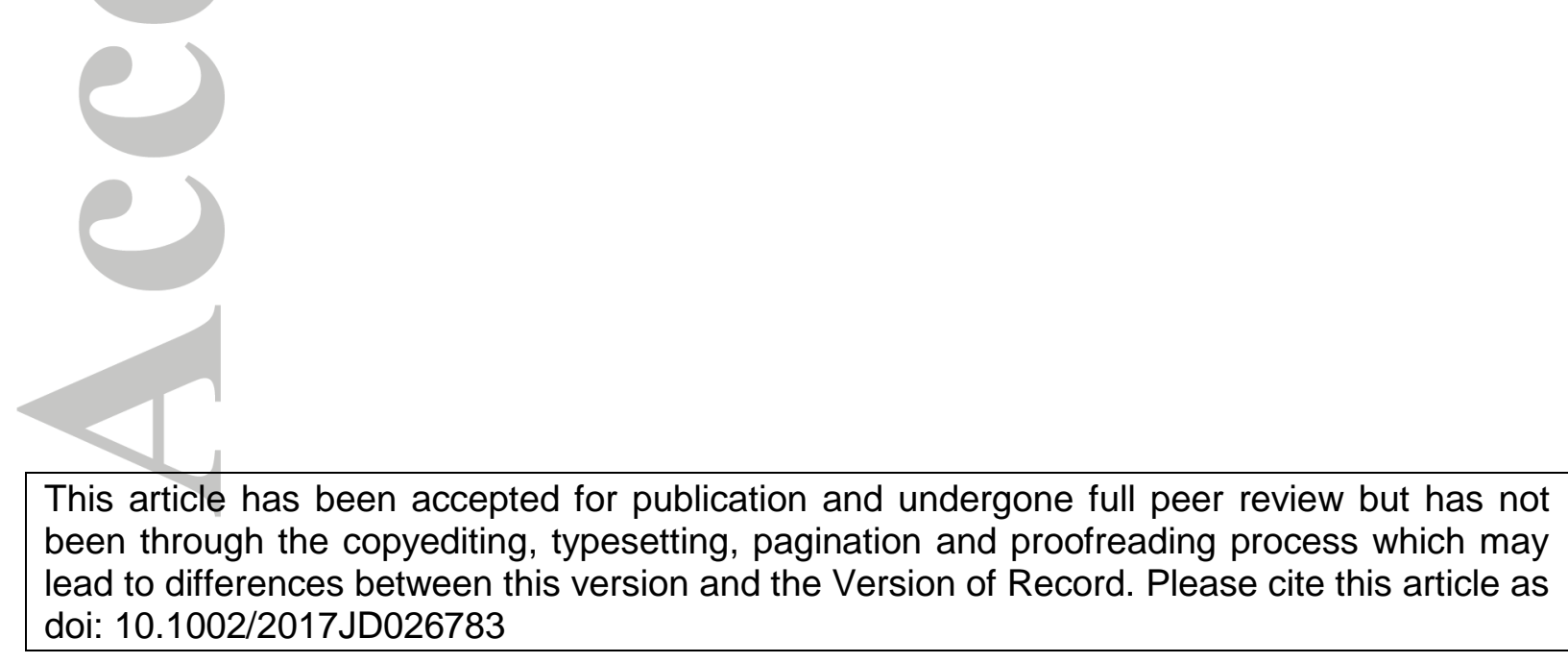




\begin{abstract}
The Middle East and North Africa (MENA) regional climate appears to be extremely sensitive to volcanic eruptions. Winter cooling after the 1991 Pinatubo eruption far exceeded the mean hemispheric temperature anomaly, even causing snowfall in Israel. To better understand MENA climate variability, the climate responses to the El Chichón and Pinatubo volcanic eruptions are analyzed using observations, NOAA/NCEP Climate Forecast System Reanalysis, and output from the Geophysical Fluid Dynamics Laboratory's High-Resolution Atmospheric Model (HiRAM). A multiple regression analysis both for the observations and the model output is performed on seasonal summer and winter composites to separate out the contributions from climate trends, El Niño Southern Oscillation (ENSO), North Atlantic Oscillation (NAO), Indian summer monsoon and volcanic aerosols. Strong regional temperature and precipitation responses over the MENA region are found in both winter and summer. The model and the observations both show that a positive NAO amplifies the MENA volcanic winter cooling. In boreal summer, the patterns of changing temperature and precipitation suggest a weakening and southward shift of the Intertropical Convergence Zone, caused by volcanic surface cooling and weakening of the Indian and West African monsoons. The model captures the main features of the climate response; however, it underestimates the total cooling, especially in winter, and exhibits a different spatial pattern of the NAO climate response in MENA compared to the observations. The conducted analysis sheds light on the internal mechanisms of MENA climate variability and helps to selectively diagnose the model deficiencies.
\end{abstract}

Key words: Explosive eruptions, ENSO, Dynamic Changes, NAO, Monsoon. 


\section{Introduction}

Large, explosive volcanic eruptions can inject millions of tons of sulfur-containing gases into the lower stratosphere. These gases oxidize into sulfuric acid, forming a sulfate aerosol plume that reflects the incoming solar radiation and cools the planet for a subsequent two to three year period [Franklin, 1784; Mitchel, 1961; Lamb, 1970; Robock, 2000; Stenchikov et al., 2009; Timmreck, 2012], affecting weather and climate. Radiative impacts of volcanic origin are important driving factors of natural climate variability [Schneider et al., 2009; Timmreck, 2012; Fyfe et al., 2013; Santer et al., 2014]. A comprehensive discussion of the role of volcanic eruptions in modulating climate can be found in [Turco et al., 1982; Briffa et al., 1998; Hansen et al., 1992; Kelly et al., 1996; Robock, 2000; Sigurdsson, 1982; Shindell et al., 2001; Stenchikov 2009; Stenchikov et al., 2009; Timmreck, 2012; Laakso et al., 2016; Kremser et al., 2016]. Volcanic eruptions have the capacity to drastically affect both global and regional climate [Timmreck, 2012; Schneider et al., 2009; Liu et al., 2016]. However, regional climate responses are poorly simulated in comparison with global ones, as volcanic forcing is naturally of global scale (so global-scale models with a relatively coarse grid spacing must be used), and resolving regional patterns requires a finer spatial resolution than conventional global models can afford.

Correct replication of climate responses to volcanic forcing is a fundamental challenge and an ultimate test for climate models attempting to simulate climate variations [Stenchikov et al., 2006; Driscoll et. al., 2012]. Strong volcanic eruptions provide an opportunity to test climate response because they produce measurable impacts for model validation [Robock, 2000]. However, volcanic impacts are short-lived, causing signals with relatively low signal-to-noise ratio, so composites or superposed epoch analysis is often used [Kirchner et al., 1999; Stenchikov et al., 2006; Driscoll et. al., 2012].

It is well known that strong equatorial explosive volcanic eruptions are followed by a pronounced positive phase of the Arctic Oscillation (AO) for one to two Northern Hemisphere winters [e.g. Robock and Mao, 1992, 1995; Robock, 2001; Robock et al., 2002; Graf et al., 1994; Shindell et al., 2001; Stenchikov et al., 2002, 2006]. The AO is defined as the first hemispheric, empirical orthogonal function of the sea level pressure variability [Thompson and Wallace, 1998, 2000] and is closely related to North Atlantic Oscillation (NAO) [Hurrell, 1995; Penner and Binyamin, 2013; Rind et al., 2005]. In the context of this study, the terms AO and NAO are interchangeable, but since we use the NAO indices of [Hurell, 1995] for our analysis, here we choose to refer to this phenomenon as NAO only. The positive phase of NAO is partly induced by an enhanced equator-to-pole temperature gradient in the lower stratosphere caused by radiative heating in the aerosol cloud over the tropics [Graf et al., 1993; Kodera, 1994; Kirchner et al., 1999]. Stenchikov et al. [2002] have proposed that ozone depletion and the tropospheric cooling effect of aerosols also contribute to the positive phase of the NAO. Tropospheric cooling caused by volcanic aerosols in the subtropics decreases the meridional temperature gradient in the winter troposphere between $30^{\circ} \mathrm{N}$ and $60^{\circ} \mathrm{N}$. The 
corresponding reduction of the mean zonal kinetic energy and the amplitudes of planetary waves in the troposphere decrease wave activity flux in the lower stratosphere. The resulting strengthening of the polar vortex forces a positive phase of the NAO [Stenchikov et al. 2002; Rind et al., 2005]. This post-eruption positive NAO phase brings anomalously warm temperature conditions to parts of America, Europe and Siberia [Groisman, 1992; Robock and Mao, 1992; Kirchner et al., 1999; Shindell et al., 2004]. This winter warming effect has received a lot of attention and was the focus of multiple studies [Robock, 2002; Stenchikov et al., 1998, 2002, 2006; Shindel et al., 2001; Fischer et al., 2007].

The Middle East climate is also strongly affected by volcanic impacts. After the 1991 Pinatubo eruption there was an unusually cold winter that led to freezing temperatures throughout the Middle East, including snowfall in Israel, during the winter of 1991-92. The post-Pinatubo winter cooling in the northern Red Sea resulted in increased deep water mixing, which provided more nutrients to algal bloom growth and caused extensive coral reef death [Genin et al., 1995; Robock, 2002]. Yu and Zhou [2004] have shown that the winter NAO has a strong negative correlation with the MENA surface air temperature in winter. A few modeling studies have mentioned the cooling anomaly over the Middle East after large eruptions [Robock and Mao, 1992; Robock, 2002; Shindell et al., 2004], indicating that it is part of a circulation response with the same origin as the winter warming in Siberia. However, there are only a few studies that have analyzed the possible physical causes of the seasonal climate variability induced by volcanic eruptions in the Middle East and North Africa region [e.g. Joseph and Zeng, 2011; Haywood et al., 2013], so the dynamic feedbacks and forced circulation changes remain poorly understood.

Along with dynamic responses, large volcanic eruptions cause significant perturbations to the hydrologic cycle [Trenberth \& Dai, 2007; Bala et al., 2008; Wild et al., 2008]. Robock and Liu [1994] used the Goddard Institute for Space Studies global climate model to analyze the precipitation response to major volcanic eruptions and noted decreases in precipitation over the Sahel region for about two years following tropical volcanic eruptions. Oman et al. [2006] found a decrease in precipitation and water discharge from the Nile River after the Laki eruption. Trenberth and Dai [2007] have used the Palmer Drought Severity Index (PDSI) to show a precipitation decrease following the Pinatubo eruption. They linked this drying to the weakening of the land-ocean temperature contrast caused by the volcanic radiative cooling that suppresses summer monsoon circulation, including the Indian, African and Asian monsoon systems, which is consistent with the results from other studies [Graf, 1992; Oman et al., 2005; Oman et al., 2006; Peng et al., 2010; Joseph and Zeng, 2011].

The tropical rain belt and the Inter-Tropical Convergence Zone (ITCZ) also respond to volcanic forcing [McCracken and Luther, 1984; Mass and Portman, 1989; Robock and Liu, 1994; Joseph and Zeng, 2011; Haywood et al., 2013; Wegmann et al., 2014; Liu et al., 2016]. Northern and Southern Hemisphere eruptions are found to have different effects on ITCZ [Haywood et al., 2013; Liu et al., 
2016; Pausata et al., 2015a, 2015b; 2016]. Based on a single eruption event, i.e. El Chichón, Haywood et al. [2013] have shown that large northern and southern hemisphere eruptions modulate the ITCZ position such that they cause drying or greening of the Sahel region. The ITCZ responses are closely related to the volcanic impact on the regional Hadley circulation [Tandon et al., 2013], which governs processes in the entire tropical belt.

Volcanic climate responses are not easily reproducible in models. Analysis of the IPCC AR4 [Stenchikov et al., 2006] and AR5 [Driscol et al., 2012] simulations indicates that the best up-to-date climate models cannot calculate the whole scale of regional winter warming or circulation responses to volcanic forcing in high northern latitudes. The winter regional responses in the MENA region, caused to a great extent by similar processes, have not been thoroughly analyzed yet, and only a few studies have been devoted to the summer regional responses. Therefore, here we try to fill this gap. We focus on atmospheric regional scale responses that are modulated by the large-scale teleconnections with ENSO, NAO or the Indian summer monsoon (ISM). To resolve regional scale and to account for the teleconnections, we use a global atmospheric model, HiRAM, with a horizontal spatial resolution of $25 \mathrm{~km}$, comparable to the resolution of regional climate models. The monthly sea surface temperature (SST) is prescribed from observations. We use state-of-the-art near-surface observations [UDEL, V2.01] and reanalysis [Saha et al., 2010] to evaluate the model capabilities and to study regional physical mechanisms that affect MENA climate sensitivity. For our analysis we choose the two strongest low-latitude tropical eruptions of the late 20th century, El Chichón of 1982 and Pinatubo of 1991, which have better observational records, having occurred in the satellite era. In this study, we address the following questions:

1. How sensitive is the MENA climate to volcano-induced radiative perturbations?

2. How are the MENA climate responses modulated by the effects of ENSO, NAO and ISM?

3. How well can HiRAM, a high-resolution atmospheric model, reproduce post-eruption direct radiative and circulation changes over the MENA region?

The rest of the paper is organized as follows. Section 2 describes the climate model, in conjunction with data and methodology used in this study. Section 3 presents results and discussion, including a detailed overview of post-eruption radiative impacts, post-eruption surface temperature and precipitation responses, obtained from both weather observations and HiRAM simulations. Sensitivity of the MENA region to circulation changes, such as ENSO, NAO and ISM, is also discussed in this section. In the last section we summarize our results.

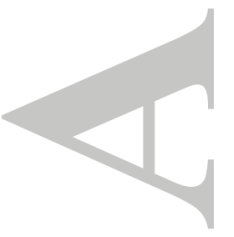




\section{Model, Data and Methodology}

\subsection{Model Description and Experimental Setup}

In this study, we employ the Geophysical Fluid Dynamics Laboratory (GFDL) global highresolution atmospheric model, HiRAM. It is based on version 2 of the GFDL Atmospheric Model [AM2; Anderson et al., 2004], with changes such as increased horizontal and vertical resolutions (up to $10 \mathrm{hPa}$ with 32 vertical layers instead of 24 , to better simulate the stratosphere and its coupling with the troposphere), and simplified parameterizations for moist convection and large-scale stratiform cloudiness. The relaxed Arakawa-Schubert convective closure scheme [Moorthi and Suarez, 1992] used in AM2 has been replaced by a shallow convective parameterization scheme [Bretherton et al., 2004]. HiRAM uses a comparatively new cubed-sphere finite-volume dynamic core [Putman and Lin, 2007], a prognostic cloud scheme with a sub-grid scale distribution of total water and multi-species tropospheric aerosol climatology precalculated using the Model for OZone and Related chemical Tracers (MOZART) [Horowitz et al., 2003]. HiRAM retains the surface flux, land surface, boundary layer, gravity wave drag, radiative transfer modules and large-scale cloud microphysics of AM2 [Anderson et al., 2004; Zhao et al., 2009]. The land model used by HiRAM, known as LM3, includes soil sensible and latent heat storage, groundwater storage, and stomata resistance [Malyshev et al., 2015].

The shortwave (SW) radiation algorithm used in HiRAM follows Freidenreich and Ramaswamy [1999]. The SW spectrum ranges from 0.17 to $4.0 \mu \mathrm{m}$ and is divided into 25 bands: 10 bands in the near IR region, 4 bands in the visible region and 11 bands in the UV region, and includes absorption by $\mathrm{H}_{2} \mathrm{O}, \mathrm{CO}_{2}, \mathrm{O}_{3}, \mathrm{O}_{2}$ and Rayleigh scattering. The longwave radiation code follows a modified form of the simplified exchange approximation [Schwarzkopf and Ramaswamy, 1999]. It accounts for the absorption and emission by the principal gases present in the atmosphere, including $\mathrm{H}_{2} \mathrm{O}, \mathrm{CO}_{2}, \mathrm{O}_{3}$, $\mathrm{N}_{2} \mathrm{O}$ and $\mathrm{CH}_{4}$, and the halocarbons, CFC-11, CFC-12, CFC-113 and HCFC-22. Aerosols and clouds are treated as absorbers in the longwave radiation code, with non-grey absorption coefficients specified in the eight spectral bands of the transfer scheme, following the methodology adopted in Ramachandran et al. [2000].

A detailed description of the model and a list of recent publications can be found at http://www.gfdl.noaa.gov/hiram.

We conducted HiRAM simulations at C360 (about $25 \mathrm{~km}$ ) resolution, typically a range that most regional climate models use in climate downscaling. This allows us to study regional climate changes using a global model that fully accounts for regional and global scale interactions, which are especially important in the tropics. A brief description of the experimental setup and methodology is as follows. 
The model is forced with the observed monthly SST from the Hadley Centre Sea Ice and Sea Surface Temperature (HadISST1) data set [Rayner et al., 2003]. The sea-ice model assumes that each grid point is either fully ice-covered or ice-free, and also assumes a uniform ice thickness of 2 meters. The anthropogenic greenhouse gases (GHGs), ozone, natural forcings, land use and tropospheric aerosol concentration in the atmosphere employed in the model follow the AMIP simulation setup, which is described in detail at http://cmip-pcmdi.llnl.gov/cmip5/forcing.html. The volcanic stratospheric aerosol spatial-time distribution and optical characteristics for both eruptions used in this model are calculated following Stenchikov et al. [2006] based on [Sato et al., 1993]. This volcanic aerosol forcing dataset provides zonally averaged, monthly mean spectral-dependent aerosol extinction, single-scattering albedo and asymmetry parameters, which are required to conduct radiative transfer simulations in the model. The indirect effect of aerosols through microphysical interaction with clouds and associated changes in cloud properties is not considered. Three different realizations were produced, each over a 33-year simulation period (1976-2008), and each beginning with different atmospheric initial conditions, taken from the GFDL long AMIP run at January 1 of years 1976, 1977, and 1978. In all three realizations, the first three years of the integration are not used in the analysis, in order to avoid spin-up effects. To reduce the effect of internal variability in the model results, we use an ensemble average over three HiRAM realizations in the analysis.

Using an atmospheric model with the prescribed SST is, of course, an idealized approach, but a fairly reasonable one, as demonstrated by our previous studies [Stenchikov et al., 2002; 2004]. The ocean effect in our simulations is not interactive but it is not absent. The observed SSTs, used in the calculations, account for the ocean post-eruption cooling. Thus, in our simulations, the atmospheric response is fully interactive and constrained by observed ocean boundary conditions. This approach allows us to evaluate the contributions of different processes more reliably and compare our results with observations.

\subsection{Observations and Reanalysis Data}

For comparison and validation of the model response, we used University of Delaware [UDEL, V2.01] monthly and global gridded $\left(0.5^{\circ}\right.$ latitude $x 0.5^{\circ}$ longitude) data of surface air temperature and precipitation fields. These data are built from a large number of station observations, both from the GHCN2 (Global Historical Climate Network) and, more extensively, from the archive of Legates \& Willmott [1990]. They are available from 1900 to 2010. The UDEL dataset covers land only. The complete description of these data and corresponding references can be found at the University of Delaware website: http://climate.geog.udel.edu/ climate/.

For the validation of the atmospheric overturning circulation and radiation fluxes, the National Center for Environmental Prediction (NCEP) Climate Forecast System (CFS) Reanalysis (CFSR) product is used [Saha et al., 2010]. CFSR is a high-resolution coupled ocean-atmosphere reanalysis, 
produced using an NCEP T382L64 (effectively $38 \mathrm{~km}$ spatial resolution) atmospheric model, coupled with the GFDL MOM4 ocean model at $0.25^{\circ}$ horizontal resolution in the tropics with 40 vertical levels. CFSR assimilates satellite observations in the form of radiance rather than retrieved values, with bias correction and spin-up runs at full resolution. CFSR also assimilates surface observations, accounts for time-varying $\mathrm{CO}_{2}$ and other radiatively absorbing gases, volcanic aerosols and solar flux variations [Saha et al., 2010]. Explicit accounting for volcanic aerosols and a high spatial resolution make CFSR especially suitable for our purposes.

\subsection{Methods}

We have analyzed climate responses during two seasons, winter (DJF) and summer (JJA), following the El Chichón eruption of April 1982 and the Pinatubo eruption of June 1991. In order to reduce noise from internal variability and to make the volcanic signal clearer, we apply a Superposed Epoch Analysis (also known as a composite analysis), which is widely used to study the effect of volcanoes on climate [Stenchikov et al., 2006; Fischer et al., 2007; Schneider et al., 2009; Peng et al., 2010]. Thus, each composite is comprised of four summers (1991, 1992, 1982 and 1983) or four winters (1991-92, 1992-93, 1982-83 and 1983-84). The anomalies are calculated with respect to the seasonal summer or winter climatology, calculated for the 30-year period 1979-2008, but excluding the two winter and summer seasons immediately following each of the volcanic eruptions.

To assess the statistical significance of the volcanic signals (total and partial, regressed on a specific index) we employ bootstrapping with replacement [Efron and Tibshirani, 1994; Xu, 2006]. The test statistic is the difference of the mean of the anomalies of a field (total or partial) corresponding to the four volcanic years and that of anomalies of the four randomly sampled nonvolcanic years. The null hypothesis $\left(\mathrm{H}_{0}\right)$ states that the difference between a four-year volcanic composited anomaly with the mean of four anomalies for randomly chosen non-volcanic years is either negligible or has an opposite sign than the volcanic anomaly. The proportion of the bootstrapped samples of the test statistic that comply with $\mathrm{H}_{0}$ is the p-value. The grid points with the p-value equal to 0.05 or less are hatched to show statistical significance at $5 \%$ (i.e., $95 \%$ confidence level, one-sided test). The identical procedure is applied to the observed and simulated fields.

To separate the contributions of multiple factors, we apply multiple linear regression analysis to the anomaly fields (for details see Section 3.3 and Appendix 1). The multiple regression technique has been widely used to separate out volcanic signals [Randel, 2010; Fujiwara et al. 2015]. In this study, we conduct multiple regressions using simulated and observed anomalies for 30 years (1979-2008) to compare the model and observed responses. To prove that the 30 -year period is sufficient, we also conduct multiple regressions using a 109-year observation period (see Appendix 2). In all cases, we include climate trend in the multiple regression (linear for the 30-year interval and polynomial for the 109-year interval) and ENSO. The effect of volcanic aerosols is considered as a residual, similar to [Randel, 2010; Fujiwara et al., 2015], to avoid losing accuracy in calculations due to close 
correlations between the ENSO and volcanic impacts, as both the El Chichón and Pinatubo eruptions occurred in El Niño years.

\section{Results and Discussion}

\subsection{Radiative Impact}

Aerosol plumes developing in the lower stratosphere after volcanic explosions modulate the climate of the earth by scattering (ultraviolet, visible and near infrared) and absorbing (near infrared) the incoming solar short-wave (SW) radiation. The presence of these scattering aerosols in the stratosphere reduces the amount of net solar radiation reaching the Earth's surface. The aerosol layer also both absorbs and emits long-wave (LW) radiation, which causes warming in the equatorial lower stratosphere and presumably forces the positive phase of NAO [Stenchikov et al., 1998; 2002; 2006]. Figure 1 shows zonal averaged aerosol optical depth (AOD) at $550 \mathrm{~nm}$, calculated over the MENA $\left(4^{\circ} \mathrm{S}-45^{\circ} \mathrm{N}\right)$ region using AOD data of Sato et al. [1993]. Both eruptions show a significant increase in the aerosol loading over the MENA region, which peaks in the fall and winter seasons of 1982 and 1991, following the El Chichón and Pinatubo eruptions, respectively. The aerosol loading decays to the background level within two to three years following each eruption. To identify the radiative impact of these volcanic aerosol plumes, the ensemble mean anomalies of the all-sky shortwave net (SWNET) radiation (positive direction is down) at the surface over the MENA region are analyzed, and the model results are compared with the CFSR product (Fig. 2). As discussed in the previous section, these fields are composited for two post-eruption seasons and for both eruptions. The CFSR and HiRAM show that the volcanic aerosols generally reduce the SWNET flux in both seasons. These changes are statistically significant at a 95\% confidence level and fall within the previously reported range of the SWNET flux anomaly produced by the El Chichón and Pinatubo volcanic plumes over the tropics and sub-tropics [Mennis et al., 1993; Stenchikov et al., 1998; Trenberth and Dai, 2007; Man et al., 2014]. The post-eruption summer and winter spatial distributions of the SWNET flux are consistent between CFSR and HiRAM. The magnitude of the negative SWNET flux anomaly in winter peaks at $-10 \mathrm{~W} / \mathrm{m}^{2}$ in CFSR and $-6 \mathrm{~W} / \mathrm{m}^{2}$ in HiRAM. Both the CFSR and HiRAM SWNET fluxes exhibit some spatial differences that could be accounted for by possible variations in the spatial distribution of cloud contents, water vapor, land surface characteristics or associated feedback processes [Hansen et al., 1981; Stenchikov et al., 1998; Soden et al., 2002; Schmidt et al., 2012].

Positive anomalies of the SWNET flux in the tropical regions of the summer hemisphere are observed in both seasons (Fig. 2) due to cloud reduction caused by post-eruption radiative cooling. Both HiRAM and CFSR clearly exhibit this feature. The magnitude of the SW heating in the summer season peaks at $10 \mathrm{~W} / \mathrm{m}^{2}$, both in HiRAM and CFSR, over the northern border of the ITCZ region that in the scope of this study we associate with the area of the upward motions in the regional Hadley cell. This suggests that the volcanic impact suppresses deep tropical convection predominantly in the summer hemisphere and weakens the rising branch of the Hadley cell over the Sahel, causing a 
southward shift of the ITCZ [Haywood et al., 2013; Joseph and Zeng, 2011]. We further discuss the complex nature of the ITCZ response in Sections 3.3 and 3.5.

Analysis of the clear-sky shortwave net flux, both at the top of the atmosphere and at the surface, shows a significant decrease during both seasons over the entire MENA domain (not shown). The clear-sky SW net flux anomaly exhibits more uniform spatial distribution than the all-sky. The warming pattern seen under all-sky conditions is not present in the clear-sky case, which confirms that a reduction in clouds is responsible for the positive SWNET anomaly in the ITCZ region.

\subsection{Total Temperature and Precipitation Response}

To quantify the MENA regional response to volcanic impacts, we first examine the total composited anomalies of surface air temperature and precipitation fields for both the model output and the UDEL observations (Fig. 3-4), and in Sections 3.3, 3.4 and 3.5 we further study the partial responses associated with different factors.

Our analysis reveals that volcanic impact causes substantial cooling (predominantly in north Africa and northern part of Arabian Peninsula) and drying over the MENA region (predominantly in central and southern areas) as shown in Fig. 3 and 4, respectively. This agrees well with previous studies [e.g. Genin et al., 1995; Robock and Mao, 1995; Robock, 2000; Shindell et al., 2004; Man et al., 2014].

The winter cooling in the UDEL observations (Fig. 3a) over the MENA region is especially strong, ranging between $-0.5 \mathrm{~K}$ and $-2.0 \mathrm{~K}$, and is almost three times the globally averaged Pinatubo temperature anomaly [Stenchikov et al., 2009; Santer et al., 2001], indicating the large sensitivity of the MENA winter climate to external radiative forcing. The model temperature responses (Fig. 3b) are smoother and the cooling signal is more uniformly distributed compared to the observations; as they are averaged over three realizations. The overall structure and geographic patterns are generally consistent between the model and observations. The cooling in Fig. 3a and $3 \mathrm{~b}$ is stronger over central and East Africa and the Arabian Peninsula, including the central and northern parts of the Red Sea, and is more pronounced in the observations than in the model simulations.

The simulated temperature response in summer is in better agreement with the observations than in winter. Figures $3 \mathrm{c}$ and $3 \mathrm{~d}$ show a strong, but weaker than in winter, cooling signal that peaks at -1.5 $\mathrm{K}$ (in observations) over the northern part of the Arabian region, and at $-0.5 \mathrm{~K}$ over the rest of the MENA domain; except for the summer tropical belt, where the positive surface air temperature anomaly peaks at $0.6 \mathrm{~K}$. This warming is consistent with the increasing all-sky SWNET flux over the tropical region (the Sahara and Sahel belt) in summer (see Fig. 2c and 2d).

A precipitation decrease ranging from -0.5 to $-1 \mathrm{~mm} /$ day, both in the observations and in the HiRAM simulations, is seen in the winter season (Fig. 4a and $4 \mathrm{~b}$ ), mainly over the tropical region. The precipitation anomaly pattern produced by the HiRAM simulation is in agreement with the observations and previously reported results [Trenberth and Dai, 2007; Fischer et al., 2007; Joseph 
and Zeng, 2011]. Trenberth and Dai [2007] also reported drying over the MENA region, particularly in the tropical region; however, they considered the annual mean responses following Pinatubo eruption, whereas we focus on the seasonal responses composited over two years following the El Chichón and Pinatubo eruptions. The post-eruption surface cooling and decreased evaporation from the ocean, causing dryness and reducing moisture transport over the MENA land areas, partially explain this effect. The volcano-induced pressure changes in the Atlantic Ocean during winter, associated with the positive NAO phase, may add to this dryness by drawing cold and dry northwesterly winds from polar areas towards the MENA domain.

In summer season (Fig. 4c and 4d), we observe a negative precipitation anomaly over almost the entire domain except in Southern Europe extending to Turkey, Syria and Iraq. A weak meridional dipole structure in the tropical region, with drying over the Sahel (up to $-1.5 \mathrm{~mm} /$ day) and an increased precipitation to the south, from $10^{\circ} \mathrm{N}$ to the equator, is seen (Fig. $4 \mathrm{c}$ and $4 \mathrm{~d}$ ). These results are consistent with a previous study by Joseph and Zeng [2011], where the post-eruption summer anomalies were composited for the Agung, El Chichón and Pinatubo eruptions. The positive summer precipitation anomalies (simulated and observed) in southern and southeastern Europe are consistent with the findings in [Fischer et al., 2007], that showed a similar pattern during the first summer following a large, explosive eruption. The precipitation anomalies in our analysis are statistically significant at a 95\% confidence level in most parts of the MENA domain.

It is well known that volcanic eruptions can affect both the Hadley circulation and precipitation in the ITCZ [Haywood et al., 2013; Pausata et al., 2015a, 2015b; 2016; Oman et al., 2006]. The African ITCZ is especially vulnerable as it experiences large seasonal migrations. The radiation, temperature and precipitation changes following a volcanic impact (Fig. 2c and 2d; Fig. 3c and 3d; Fig.4c and 4d) are generally consistent with a weakening and southward shift of the ITCZ. To test this theory, we analyze the vertical mass flux $\mathrm{M}_{\Phi}$ in a regional Hadley circulation, separated from the Walker mass flux following [Schwendike et al., 2014; Bangalth and Stenchikov, 2015]. Figures 5a and 5b show the total regional JJA mass flux $\mathrm{M}_{\Phi}$ at $500 \mathrm{hPa}$, averaged over the 1979-2008 period as a function of latitude $\Phi$ and longitude $\lambda$, both for the CFS reanalysis and the HiRAM simulations. The CFSR $M_{\Phi}$ is spatially a little more compact with a more pronounced core than in the model, but the resemblance to HiRAM is quite good. The model captures correctly even small areas of upward motion over the eastern Mediterranean Sea and the northwestern coast of Africa in summer season that presumably are forced by the orography [Simpson et al., 2015]. Figures 5c and 5d show the composite responses of $\mathrm{M}_{\Phi}$ to the volcanic impact. The $\mathrm{M}_{\Phi}$ anomalies, although weaker in the model, are fairly consistent with the reanalysis, showing the weakening of the large-scale subsidence over the Mediterranean, and the strengthening of the upward motion at $0<\Phi<10^{\circ} \mathrm{N}$, especially in central and East Africa. In West Africa, the weakening of $\mathrm{M}_{\Phi}$ in the West African monsoon dominates. Thus, despite the weakening and southward shift of cloudiness and ITCZ seen across the entire continent, the driving mechanisms of this effect on West and East Africa could be quite different. The Indian and African monsoon 
systems are tightly linked to the rising branch of local Hadley cell [Joseph and Zeng, 2011; Wegman et al., 2014], and the post-eruption anomalies of $\mathrm{M}_{\Phi}$ over the MENA tropics could be modulated by changes in the Indian and African monsoon systems [Wegman et al., 2014].

Presumably, the meridional dipole pattern in the summer precipitation response seen in Figures 4c and $4 \mathrm{~d}$ in the tropics, which forms because the West African monsoon (WAM) circulation is suppressed and the ITCZ shifts southward, is induced by both direct volcanic radiative cooling and circulation changes. The suppression of the regional WAM system is caused by a change in the thermal contrast between the Gulf of Guinea and African landmasses as well as between the Arabian Sea and the nearby continental Arabian Peninsula [Haywood et al., 2013]. Oman et al. [2005; 2006] have also reported a decrease in cloud amount after the Katmai eruption of 1912, as a result of a posteruption weakening of the Indian and African summer monsoon systems and an associated reduction in precipitation and Nile water discharge.

Summarizing the total regional climate response in MENA, we conclude that the model and observations show that cooling is more pronounced in boreal winter (in observations the winter temperature change is up to $1 \mathrm{~K}$ colder than in summer) than in the boreal summer (Fig. 3), although the radiative forcing is not very different (Fig. 2). This suggests the contribution of an additional "dynamically forced" cooling, caused by circulation changes associated with the forced positive phase of the NAO. Summer responses over the MENA region are strongly affected by the weakening of the monsoon circulation, the shift in the ITCZ and the drying in the Sahel. Thus the preliminary analysis shows that the MENA regional climate responses to volcanic forcing are modulated by multiple factors, e.g. NAO in winter and ISM in summer. Both seasons are affected by the ENSO phase and climate trends must be accurately removed. To better understand the driving mechanisms and to clearly reveal the model deficiencies, in the next section we conduct a multiple linear regression analysis that, in the first approximation, allows us to delineate the contributions from different physical processes.

\subsection{Delineating the Effects of NAO, ENSO, ISM and Volcanic Aerosols}

NAO, ENSO and ISM are the major external circulation modes that affect the MENA climate [Wanner et al., 2001; Aiki et al., 2006; Camberlin et al., 2010; Josey et al., 2011; Flaounas et al., 2012; Papadopoulos et al., 2013; Abualnaja et al., 2015]. WAM is considered to be internal to MENA. There are a few other circulation modes with origins in the Atlantic sector that have been shown to induce climate changes over the Mediterranean Middle East, such as the East Atlantic (EA) and East Atlantic / West Russia (EA/WR) patterns. However, their contribution to MENA regional climate variability is much smaller than NAO, ENSO or ISM [Wanner et al., 2001; Krichak et al., 2002; Lim, 2015]. We also tested the impact of the Indian Ocean Dipole (IOD) on the MENA region and found it negligibly small. The Atlantic Multi-Decadal Oscillation (AMO) introduced in 
[Schesinger and Ramankuttu, 1994] is an important control on much longer time scales than those considered here.

Thus, in the winter season we perform the multiple regression analysis by employing a climate trend index (which references the calendar year of the studied season), the ENSO index (DJF sea surface temperature anomaly in the Niño 3.4 region) and the NAO index [Hurrell, 1995; Hurrell and Deser, 2010]; whereas in the summer season we consider the climate trend index, the ENSO index and the Indian summer monsoon rainfall index (IMI) introduced in [Parthasarathy et al., 1994; Parthasarathy, 1995], as a total summer rainfall computed over the entire Indian region. The selection of these indices for the winter or summer season is based on their relevance to this region as discussed in [Josey et al., 2011; Papadopoulos et al., 2013; Abualnaja et al., 2015], as well as on our own experience (i.e. the selected predictors have significant correlation with MENA temperature and precipitation fields in a corresponding season). All the predictors (Fig. 6) used in the multiple regression analysis (NAO, ENSO and IMI) are standardized. The residual anomalies are interpreted as a volcanic impact [Randel, 2010; Fujiwara et al., 2015]; however, they might absorb some (presumably small) contributions from the internal variability and the factors that are not included in the multiple regressions, e.g. IOD or EA/WR (see Figures S1 and S2 in the supplementary materials section). The multiple regression analysis used in this study is discussed in detail in Appendix 1. Additionally, we perform multiple regression analysis over a longer 109-year period (1900-2008) using UDEL observations, to test the robustness and significance of the results obtained using a 30year (1979-2008) simulation period (Appendix 2).

\subsection{Winter Climate Response}

\subsubsection{ENSO}

ENSO is a leading source of climate variability seen both in the ocean and the atmosphere [Trenberth et al., 1998; Trenberth and Caron, 2000; Timmermann et al., 1999]. Global atmospheric teleconnections from ENSO cause extreme weather events, droughts, flooding and changes to tropical cyclone activity [Chan, 1985; Nicholls, 1985; Power et al., 1999]. The ENSO impact on global and regional temperatures and precipitation patterns have been widely discussed [Trenberth et al., 1998; Timmermann et al., 1999; Ashok et al. 2004; 2007; Zhang et al., 2013; 2015].

It has been shown that an El Niño event has the potential to modulate a volcanic signal [Mass and Portman, 1989; Portman and Gutzler, 1996; Timmreck, 2012; Robock et al., 1995]. The last three major volcanic eruptions, Agung (1963), El Chichón (1982) and Pinatubo (1991), coincided with El Niño events [Trenberth and Dai, 2007; Timmreck, 2012]; therefore, the extraction of ENSO signals using simple linear regression was suggested by Robock and Liu [1994] while discussing volcanic impacts. Here we make use of multiple linear regression to simultaneously account for multiple interfering factors. ENSO has a reasonably high correlation with MENA winter and summer surface 
temperatures, suggesting that it could play a role in modulating climate response in this region.

Figures $7 \mathrm{a}$ and $7 \mathrm{~b}$ show the regressed (in the observations and simulations) impact of ENSO on temperature in winter over the MENA region. The model underestimates the magnitude of ENSO winter cooling compared to the observations, although their overall spatial patterns are coherent. The observations show a stronger cooling anomaly over Sudan and parts of the Arabian Peninsula than in the HiRAM simulations, however the 109-year observational analysis appears to be more consistent with the model (see Appendix 2). Both the observations and the model show similar warming signals over parts of Afghanistan, Turkmenistan, Yemen, Ethiopia, South Sudan, Liberia, Guinea, Mauritania and Western Sahara. Figures 7c and 7d show ENSO-induced precipitation anomalies over the MENA region. Drying anomalies of 0.1 to $0.2 \mathrm{~mm} /$ day are scattered over the entire region, and are less pronounced and less organized in specific spatial patterns than the temperature responses.

\subsubsection{NAO}

The NAO effect on southern Europe and the Mediterranean Middle East was discussed in [Wallace and Gutzler, 1981; van Loon and Rogers, 1978; Cullen et al., 2002; Iqbal et al., 2013]. It was also observed that large equatorial explosive eruptions of a size comparable to El Chichón and Pinatubo strengthen and force the NAO towards its positive phase [Stenchikov et al., 2002, 2006], causing a poleward shift of the subtropical jet and the storm tracks in the Northern Hemisphere boreal winter. The associated winter warming in northern high latitude regions covering Eurasia and North America [Baldwin and Dunkerton, 1999; Kirchner et al., 1999; Kodera et al., 1995, Graf et al., 1993; Robock, 2002; Stenchikov et al., 2002, 2006] was a subject of intensive research during the past decade. Here we focus on the forced NAO effect in the MENA region.

Figure 8 displays NAO-regressed composited anomalies of surface air temperature and precipitation that show the substantial post-eruption cooling and drying over the MENA region in the winter season. The magnitude of NAO-induced simulated winter cooling reaches $-0.35 \mathrm{~K}$ compared with $-0.6 \mathrm{~K}$ in the observations (Fig. $8 \mathrm{a}$ and $8 \mathrm{~b}$ ). The HiRAM NAO winter cooling signal is twice as weak as the observations. The spatial pattern of the NAO-regressed surface temperature anomaly is also not very well reproduced by the model, which shows maximum cooling in central Africa, while in observations the maximum cooling is seen in the northwest of Africa. This discrepancy between the simulated and observed anomalies could be partly attributed to the internal variability but, because anomalies are statistically significant both in the model and in observations, we relate the discrepancy more to the model deficiency (see Figures S3 and S4 in the supplementary materials section). The pattern of the NAO-induced precipitation anomaly is largely consistent between the model and observations (Fig. 8c and 8d). The NAO precipitation anomaly peaks at $-0.2 \mathrm{~mm} / \mathrm{day}$, both in the model and the observations. Drying is more pronounced over southeastern Europe, the northern part of the Arabian Peninsula (Syria, Jordan and Iraq) and over the tropical region, than in central Africa, where either no precipitation changes or a very weak signal is observed. 


\subsubsection{Volcanic Radiative Cooling}

Figure 9 shows the residual winter season anomalies of surface air temperature and precipitation, calculated by subtracting linear trend, ENSO and NAO-regressed fields from the total anomaly (Fig. 3a-b and Fig. 4a-b). Both the model and the observations display a significant cooling signal over the entire MENA domain that is, presumably, caused by the reflection of the incoming shortwave radiations by stratospheric volcanic aerosols following the volcanic eruptions. The observed volcanic winter cooling signal is strong over the Arabian Peninsula $(-1.2 \mathrm{~K})$ and northeastern Africa $(-0.6 \mathrm{~K})$, but in the simulations, it peaks at $-0.4 \mathrm{~K}$ in western Africa and in the center of the Arabian Peninsula. The model slightly underestimates the volcanic cooling and exhibits marginally different spatial cooling patterns; however, the overall anomaly structure is consistent with the observations. The precipitation decreases in the tropics south of $10^{\circ} \mathrm{N}$, both in the model and the observations, due to radiative cooling. The model does not capture drying signals on the Mediterranean coasts, or in Spain, Iran or Afghanistan. However, it does show the correct signal over Turkey.

\subsection{Summer Climate Response}

\subsubsection{ENSO}

Typically, ENSO peaks in winter, but, as its development starts a year before the peak and its decay extends to a year after, it could modulate a volcanic signal during the summer season [Zhang et al., 2013]. Volcanic eruptions could also trigger El Niño-like SST anomalies. Northern Hemisphere high-latitude eruptions during the summer force an El Niño within the following 8-9 months, through a southward shift of the ITCZ [Pausata et al., 2015a; 2015b; 2016]. Tropical low-latitude eruptions tend to enhance El Niño-like anomalies for the following 12 months after an eruption [Predybaylo et al., 2017; Adams et al., 2003; Mann et al., 2005; Emile-Geay et al., 2008; Ohba et al., 2013; Maher et al., 2015].

Figures 10a and 10b show the composited MENA climate response (in observations and in the model) associated with the winter positive ENSO phase occurring in the years of the El Chichón and Pinatubo volcanic eruptions. Both the model and observations depict a spatially fairly uniform warming signal of 0.1-0.2 K, except over the northern Arabian Peninsula, southern Europe, and northwestern Africa, where a cooling signal is observed instead. The temperature response is consistent spatially and quantitatively in the model and the observations. The drying effect (Fig. 10c and $10 \mathrm{~d}$ ) is seen over the tropical regions, except some areas of North Africa and southern Europe, where increased precipitation is detected. Both the magnitude and the spatial structure of ENSOinduced precipitation anomalies are in good agreement between the observations and the HiRAM simulation. The significant drying of the northern tropics (including WAM and East Africa) suggests an overall suppression of convective activity because of the ENSO-induced change to the Hadley and 
Walker circulations, resulting in less cross-equatorial moisture transport from the ocean towards inland areas [see e.g. Shukla, 1975; Ashok et al., 2004; 2007; Dogar et al., 2017].

\subsubsection{Indian Summer Monsoon}

Strong volcanic eruptions suppress the ISM [Oman et. al., 2006; Trenberth and Dai, 2007; Anchukaitis et al., 2010; Joseph and Zeng, 2011; Liu et al., 2016; Robock and Liu, 1994; Robock et al., 2008], through solar dimming and weakening of the temperature contrast between the continents and the ocean. In turn, the ISM profoundly affects summer circulation over the tropical MENA region [Rodwell and Hoskins, 1996; Sultan and Janicot, 2000].

The weakening of the ISM causes a warming and drying anomaly over the $15^{\circ} \mathrm{N}$ tropical belt (Fig. 11). Warming reaches $0.15 \mathrm{~K}$, both in the model and the observations. HiRAM shows a better organized tropical warming pattern compared to the UDEL observations, because the model anomalies are built using three realizations and do not suffer from insufficient data coverage, as the observations do. The warming pattern is consolidated over the summer ITCZ region, and can be attributed to the weakening and southward shifting of the regional Hadley cell.

Drying southward of $20^{\circ} \mathrm{N}$ (the Sahel region) is found both in the model and observation in Figures $11 \mathrm{c}$ and $11 \mathrm{~d}$, peaking at $-0.2 \mathrm{~mm} /$ day. At the same time, precipitation from the WAM and in central equatorial Africa increases. The model results are fairly consistent with the UDEL observed pattern, which indicates the model's potential to simulate the Indian summer monsoon effect in the MENA region. The ISM-contributed precipitation anomaly shows a meridional dipole pattern (decreasing precipitation north of $10^{\circ} \mathrm{N}$ but increasing south of $10^{\circ} \mathrm{N}$, in central and West Africa) that is consistent with the southward shift of the ITCZ [Haywood et al., 2013; Joseph and Zeng, 2011] and the strengthening of the coastal monsoon circulation in West Africa.

Tropical East Africa and the Arabian Peninsula experience drying of $0.1-0.2 \mathrm{~mm} / \mathrm{day}$ due to the weakening of the Somali Jet, which drags moisture towards the inland regions of East Africa (Somalia, Ethiopia, Djibouti and Eritrea) and the southern parts of the Arabian Peninsula, including Yemen and Oman. The suppression of the ISM by volcanic cooling weakens the Somali Jet, resulting in less transport of moisture to eastern Africa [Aiki et al., 2006], and consequently weakens the Hadley updraft motion, contributing to the southward shift of the ITCZ and even affecting the West African monsoon [Camberlin et al., 2010; Flaounas et al., 2012].

\subsubsection{Volcanic Radiative Cooling}

Figure 12 shows the residual anomaly of surface air temperature and precipitation in the summer season, computed by subtracting the regressed impacts of climate trend, ENSO and the Indian monsoon from the corresponding total anomaly. Cooling (Fig. 12a and 12b) is seen over most of the MENA region, except the tropical belt, West Africa and the Horn of Africa, where we see warming in both the model and the observations. This warming is consistent with the southward shift 
of the ITCZ and suppression of the WAM. Cooling reaching $0.5 \mathrm{~K}$ is more pronounced over Western Sahara, Morocco and the Arabian Peninsula (Jordan, Syria, Iraq and Saudi Arabia), both in the model and the observations; we attribute this to the radiative cooling of volcanic aerosol and the associated feedbacks [Atwater, 1970; Mitchell, 1971; Crutzen, 2006; Hatzianastassiou et al., 2007].

Both the model and the observations depict a significant decrease in precipitation (Fig. 12c and $12 \mathrm{~d}$ ), peaking at $-0.6 \mathrm{~mm} /$ day (nearly half of the total anomaly), over the African tropical regions south of $20^{\circ} \mathrm{N}$, especially during the WAM. The drying in East Africa south of $10^{\circ} \mathrm{N}$ peaks at -0.5 $\mathrm{mm} /$ day. The precipitation anomalies over the Arabian Peninsula are largely inconsistent between the model and the observations. In summer, the ITCZ, associated with the upward branch of the regional Hadley Circulation, moves northward as a result of the seasonal increase of solar heating in the Northern Hemisphere. But solar dimming caused by volcanic aerosols suppresses the northward migration of ITCZ, resulting in a decreased cloud amount and an associated decrease in rainfall over the tropical ITCZ region. The post-eruption weakening of WAM, seen in Fig. 12c and 12d, is consistent with the decrease in the Hadley vertical mass flux in this region (Fig. 5). It causes reduced moisture transport to the tropical Saharan rain belt and the summer ITCZ region, amplifying the drying effect.

The warming and drying belt at $15^{\circ} \mathrm{N}$ has a quasi-dipole meridional structure and is formed by the southward retreat of the ITCZ in central and East Africa. Warming along the $15^{\circ} \mathrm{N}$ belt is caused by a decrease in the cloud amount and a resulting increase in the net shortwave radiation reaching the surface. This belt-like anomaly is better seen in the model than in observations, probably because of natural variability and scarce measurements for this region. Increased precipitation over the Horn of Africa is due to the southward shift of the ITCZ and the increased vertical mass flux $\mathrm{M}_{\Phi}$ in this region (Fig. 5).

\section{Summary and Conclusions}

The strong regional circulation anomalies, along with direct volcanic aerosol radiative cooling, cause an enormously strong climate response over the MENA region. To better quantify these effects, we use UDEL observations, high-resolution (with the effective $38 \mathrm{~km}$ grid spacing) CFS reanalysis that accounts for volcanic aerosols and a GFDL global HiRAM with the effective $25 \mathrm{~km}$ grid spacing. Our study focuses on the winter and summer seasons, and anomalies are composited for two eruptions (El Chichón and Pinatubo) and two post-eruption years, to make the results more statistically stable. We analyze changes in solar radiation, surface temperature, cloud amount and precipitation, comparing the model responses with the UDEL temperature and precipitation observations, and the CFSR solar radiation and vertical mass flux anomalies. The high-resolution global HiRAM simulations and CFSR ensure the grid resolution is amply sufficient for regional climate analysis, with the ability to account for interactions (teleconnections) among processes on the global and regional 
scales.

We assume that the MENA region is affected by both direct volcanic radiative cooling from within the region and by teleconnections from outside the region, which are partly enforced by the volcanic radiative effect and partly caused by natural variability. The rationale of this study is to decompose, using multiple linear regressions, both the observed and simulated total volcanic impacts into the effects of the direct radiative cooling within the MENA region and external teleconnections, and then use this analysis to evaluate the physical mechanisms of regional climate sensitivity and the model performance. The external factors we consider include ENSO, NAO and ISM. Climate trends are also included in the multiple regressions. The volcanic effect on NAO and ISM is calculated within the model, but ENSO and SST are prescribed from the observations. The residuals of the multiple regression analysis are attributed to the effect of direct volcanic cooling, as discussed above in section 2.3 and 3.3. ENSO, climate trend and volcanic forcing contributions are accounted for in both summer and winter, while the NAO and ISM effects are calculated only for winter or summer, respectively.

We find strong precipitation and temperature anomalies in our composites during both seasons. The MENA temperature composited anomalies peak at $-1.5 \mathrm{~K}$, which is three times the observed global cooling after the Pinatubo eruption.

In winter, both the observations and the model-based analysis suggest that most of the total posteruption cooling over the MENA region is contributed by the anomalously positive NAO, and less by the direct regional radiative cooling (see Fig. 8 and 9). Both the direct volcanic effect and the NAO reduce precipitation in tropical Africa, but the positive ENSO enhances precipitation over the Horn of Africa. The observed ENSO effect is relatively strong, causing cooling in eastern and central Africa, the Middle East, and the eastern Mediterranean. This is not well captured by the model.

The positive phase of NAO is observed after major equatorial volcanic eruptions like El Chichon and Pinatubo. It is forced by heating of the equatorial lower stratosphere by volcanic aerosols and by an increasing equator-to-pole temperature gradient in the lower stratosphere [Stenchikov et al., 2002; 2004, 2006]. The NAO response is affected by internal variability. The up-to-date climate models underestimate the NAO response (see, e.g., Driscoll et al., 2011; Stenchikov et al., 2006). However, in our simulations and in the observations, this effect is generally statistically significant.

In summer, the decrease in the thermal gradient between the ocean and the MENA landmasses caused by the direct volcanic cooling weakens the African branch of the Hadley cell and the WAM. The ISM plays a significant role in weakening the Hadley circulation, and in strengthening coastal precipitation both in West Africa and over the Horn of Africa to the east. The overall drying anomaly during summer from radiative cooling is enhanced over the northern border of the rain belt and the Sahel region by a post-eruption reduction of the ISM and WAM rainfall. The cloud amount pattern and associated changes in precipitation over the interior of the African continent suggest a southward shift of the Northern Hemisphere summer ITCZ, facilitated by volcanic cooling and weakening of the 
ISM. A decrease in cloud amount over the MENA tropical belt in the summer season regionally increases downward solar radiation, worsening draught conditions. However, overall cloudiness increases.

The diagnosis of the regional Hadley cell vertical mass flux $\mathrm{M}_{\Phi}$ over the MENA region (Fig. 5) is consistent with these findings and shows a weakening of the large-scale subsidence over the Mediterranean, due to damping of the ISM, weakening $\mathrm{M}_{\Phi}$ over the Sahara and at the northern border of the ITCZ, and strengthening $\mathrm{M}_{\Phi}$ south of $15^{\circ} \mathrm{N}$, associated with the southward shift of the ITCZ. The ITCZ shift is more uniform in central and East Africa, while decreased $\mathrm{M}_{\Phi}$ in the WAM is seen in West Africa. It is especially pronounced in the HiRAM simulations. Thus, decreased cloud amount at the northern border of the ITCZ in central and East Africa is caused by the weakening of the local Hadley cell and a southward shift of the ITCZ, but in West Africa decreased moisture is dominated by the weakening of the WAM.

The HiRAM simulations, with effective $25 \mathrm{~km}$ grid spacing, resolve the regional processes in the MENA region and reproduce well the radiative forcing in comparison with the CFSR and previous studies. This high-resolution atmospheric model is an ideal tool for regional impact studies, as it has the spatial resolution of a regional model but interactively accounts for teleconnections. However, we find that HiRAM largely underestimates winter cooling due to a weaker NAO response and generates an incorrect NAO spatial pattern over the MENA region. This is consistent with the finding that global climate models have shown an inability to fully reproduce the seasonal and regional nature of volcano-induced climate change [Stenchikov et al., 2006; Otterå, 2008; Driscoll et al., 2012]. The model performs much better in the summer season, capturing well the volcanic direct radiative impacts over the MENA region and the impact of the ISM on the WAM.

This analysis provides a useful test of the mechanistic regional behavior of the state-of-the-art global high-resolution atmospheric model, HiRAM, in reproducing post-eruption climate changes over the MENA region, and evaluates the major teleconnections (ENSO, NAO and ISM) that affect the MENA region. It further emphasizes that the MENA climate regime is highly sensitive to volcanic impacts, and improving simulation of NAO, ENSO and ISM is crucially important for better simulating climate variability and change in the MENA region. Strong low-latitude eruptions have the potential to affect agricultural productivity, especially in the Sahel region, possibly leading to famine and severely influencing the lives of the African inhabitants [http://www.unep.org/dewa/Africa/publications/AEO-1/056.htm].

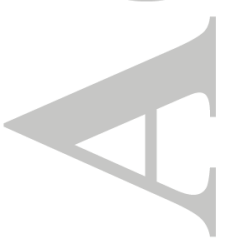




\section{Appendix 1. Multiple Linear Regression Analysis}

The multiple linear regression technique is an extension of the simple linear regression used when more than one independent factor (also known as a predictor, regressor or controlled variable) affects a dependent variable (also known as a response variable, measured variable, outcome, regressand or predictand). As dependent variables we choose $T_{W}^{i}(\lambda, \phi)$ - winter temperature anomaly, $P_{W}^{i}(\lambda, \phi)$ - winter precipitation anomaly, $T_{S}^{i}(\lambda, \phi)$ - summer temperature anomaly and $P_{S}^{i}(\lambda, \phi)$ summer precipitation anomaly, which are functions of longitude $\lambda$, latitude $\phi$ and the time index $i$, which reflects the year of a season and spans all years in the dataset. As predictors we choose:

Trend index $\alpha_{T R}^{i}$ - the standardized year of the season,

ENSO index $\alpha_{E N S O}^{i}$ - the standardized DJF NINO3.4 index,

NAO index $\alpha_{N A O}^{i}$ - the standardized DJF NAO index of Hurel [1993] and

ISM index $\alpha_{I S M}^{i}$ - the standardized JJA Indian Monsoon rainfall index,

which depend only on the time index $i$. Since the predictors are all standardized, the regression relations take the following forms for winter:

$$
\begin{aligned}
& T_{W}^{i}(\lambda, \phi)=\alpha_{T R}^{i} \times T_{T R}^{W}(\lambda, \phi)+\alpha_{E N S O}^{i} \times T_{E N S O}^{W}(\lambda, \phi)+\alpha_{N A O}^{i} \times T_{N A O}^{W}(\lambda, \phi) \\
& P_{W}^{i}(\lambda, \phi)=\alpha_{T R}^{i} \times P_{T R}^{W}(\lambda, \phi)+\alpha_{E N S O}^{i} \times P_{E N S O}^{W}(\lambda, \phi)+\alpha_{N A O}^{i} \times P_{N A O}^{W}(\lambda, \phi)
\end{aligned}
$$

and for summer:

$$
\begin{aligned}
& T_{S}^{i}(\lambda, \phi)=\alpha_{T R}^{i} \times T_{T R}^{S}(\lambda, \phi)+\alpha_{E N S O}^{i} \times T_{E N S O}^{S}(\lambda, \phi)+\alpha_{I S M}^{i} \times T_{I S M}^{S}(\lambda, \phi) \\
& P_{S}^{i}(\lambda, \phi)=\alpha_{T R}^{i} \times P_{T R}^{S}(\lambda, \phi)+\alpha_{E N S O}^{i} \times P_{E N S O}^{S}(\lambda, \phi)+\alpha_{I S M}^{i} \times P_{I S M}^{S}(\lambda, \phi)
\end{aligned}
$$

where $T_{T R}^{W, S}, P_{T R}^{W, S}, T_{E N S O}^{W, S}, P_{E N S O}^{W, S}, T_{N A O}^{W}, P_{N A O}^{W}, T_{I S M}^{S}, P_{I S M}^{S}$ are the regression coefficients that for each $(\lambda, \phi)$ can be obtained from the following systems of linear algebraic equations for winter:

$$
\begin{aligned}
\operatorname{Cov}\left(\alpha_{T R}^{i}, T_{W}^{i}\right) & =T_{T R}^{W}+\operatorname{cov}\left(\alpha_{T R}^{i}, \alpha_{E N S O}^{i}\right) \times T_{E N S O}^{W}+\operatorname{cov}\left(\alpha_{T R}^{i}, \alpha_{N A O}^{i}\right) \times T_{N A O}^{W} \\
\operatorname{Cov}\left(\alpha_{E N S O}^{i}, T_{W}^{i}\right) & =\operatorname{cov}\left(\alpha_{T R}^{i}, \alpha_{E N S O}^{i}\right) \times T_{T R}^{W}+T_{E N S O}^{W}+\operatorname{cov}\left(\alpha_{E N S O}^{i}, \alpha_{N A O}^{i}\right) \times T_{N A O}^{W} \\
\operatorname{Cov}\left(\alpha_{N A O}^{i}, T_{W}^{i}\right) & =\operatorname{cov}\left(\alpha_{T R}^{i}, \alpha_{N A O}^{i}\right) \times T_{T R}^{W}+\operatorname{cov}\left(\alpha_{N A O}^{i}, \alpha_{E N S O}^{i}\right) \times T_{E N S O}^{W}+T_{N A O}^{W} \\
\operatorname{Cov}\left(\alpha_{T R}^{i}, P_{W}^{i}\right) & =P_{T R}^{W}+\operatorname{cov}\left(\alpha_{T R}^{i}, \alpha_{E N S O}^{i}\right) \times P_{E N S O}^{W}+\operatorname{cov}\left(\alpha_{T R}^{i}, \alpha_{N A O}^{i}\right) \times P_{N A O}^{W} \\
\operatorname{Cov}\left(\alpha_{E N S O}^{i}, P_{W}^{i}\right) & =\operatorname{cov}\left(\alpha_{T R}^{i}, \alpha_{E N S O}^{i}\right) \times P_{T R}^{W}+P_{E N S O}^{W}+\operatorname{cov}\left(\alpha_{E N S O}^{i}, \alpha_{N A O}^{i}\right) \times P_{N A O}^{W} \\
\operatorname{Cov}\left(\alpha_{N A O}^{i}, P_{W}^{i}\right) & =\operatorname{cov}\left(\alpha_{T R}^{i}, \alpha_{N A O}^{i}\right) \times P_{T R}^{W}+\operatorname{cov}\left(\alpha_{N A O}^{i}, \alpha_{E N S O}^{i}\right) \times P_{E N S O}^{W}+P_{N A O}^{W}
\end{aligned}
$$

and for summer:

$$
\begin{gathered}
\operatorname{Cov}\left(\alpha_{T R}^{i}, T_{S}^{i}\right)=T_{T R}^{S}+\operatorname{cov}\left(\alpha_{T R}^{i}, \alpha_{E N S O}^{i}\right) \times T_{E N S O}^{S}+\operatorname{cov}\left(\alpha_{T R}^{i}, \alpha_{I S M}^{i}\right) \times T_{I S M}^{S} \\
\operatorname{Cov}\left(\alpha_{E N S O}^{i}, T_{S}^{i}\right)=\operatorname{cov}\left(\alpha_{T R}^{i}, \alpha_{E N S O}^{i}\right) \times T_{T R}^{S}+T_{E N S O}^{S}+\operatorname{cov}\left(\alpha_{E N S O}^{i}, \alpha_{I S M}^{i}\right) \times T_{I S M}^{S} \\
\operatorname{Cov}\left(\alpha_{N A O}^{i}, T_{S}^{i}\right)=\operatorname{cov}\left(\alpha_{T R}^{i}, \alpha_{N A O}^{i}\right) \times T_{T R}^{S}+\operatorname{cov}\left(\alpha_{N A O}^{i}, \alpha_{E N S O}^{i}\right) \times T_{E N S O}^{S}+T_{I S M}^{S}
\end{gathered}
$$




$$
\begin{gathered}
\operatorname{Cov}\left(\alpha_{T R}^{i}, P_{S}^{i}\right)=P_{T R}^{S}+\operatorname{cov}\left(\alpha_{T R}^{i}, \alpha_{E N S O}^{i}\right) \times P_{E N S O}^{S}+\operatorname{cov}\left(\alpha_{T R}^{i}, \alpha_{I S M}^{i}\right) \times P_{I S M}^{S} \\
\operatorname{Cov}\left(\alpha_{E N S O}^{i}, P_{S}^{i}\right)=\operatorname{cov}\left(\alpha_{T R}^{i}, \alpha_{E N S O}^{i}\right) \times P_{T R}^{S}+P_{E N S O}^{S}+\operatorname{cov}\left(\alpha_{E N S O}^{i}, \alpha_{I S M}^{i}\right) \times P_{I S M}^{S} \\
\operatorname{Cov}\left(\alpha_{N A O}^{i}, P_{S}^{i}\right)=\operatorname{cov}\left(\alpha_{T R}^{i}, \alpha_{N A O}^{i}\right) \times P_{T R}^{S}+\operatorname{cov}\left(\alpha_{N A O}^{i}, \alpha_{E N S O}^{i}\right) \times P_{E N S O}^{S}+P_{I S M}^{S}
\end{gathered}
$$

where $C o v$ is a covariance operator. The residuals in (1-4) are treated as a direct volcanic effect. For more details see [Gujarati, 2009].

\section{Appendix 2. Multiple Regression on the 30-Year and 109-Year Datasets}

In order to test the robustness and statistical stability of our results, we conduct a multiple regression analysis using UDEL observations over almost the entire period for which they are available (1900-2008). We follow the same multiple regression procedure as is used for the analysis over the 30-year (1979-2008) period; however, the climate trend over the 109-year period is not linear and we have to consider a polynomial trend. As in the main part of the paper, the results are presented as DJF and JJA two-year composites following the El Chichón and Pinatubo eruptions. Assuming that volcanic eruptions and El Niño events are relatively rare, a comparison of the results from the 30-year analysis with those conducted for a considerably longer period will certainly increase the confidence in our results.

Figure 13 shows a comparison of the NAO-regressed anomaly patterns for winter surface temperature and precipitation fields, calculated using the 30 and 109-year observations, following both the eruptions. These plots show that the volcanically enhanced positive phase of NAO induces consistent surface temperature and precipitation patterns at both time scales, indicating that our 30year results are robust. The 109-year anomalies are slightly more statistically significant, as expected. Figure 14 shows the ENSO-regressed winter anomalies of surface air temperature and precipitation for the 30-year and 109-year periods. The anomalies are largely consistent; however, the 109-year cooling response over the Arabian Peninsula and East Africa is somewhat weaker and closer to the model prediction (Fig. 7a and 7b) than the 30-year, and both precipitation and temperature anomalies are more statistically significant in the 109-year analysis. The comparison of the 30-year ENSOregression analysis during summer with that conducted for a longer period clearly shows consistent warming and drying anomalies over the tropical region (Fig. 15), similar to what we see during winter. Figure 16 compares the 30-year and 109-year-regressed ISM temperature and precipitation anomalies; they appear to be very consistent with wider areas of statistical significance and a slightly stronger drying in the 109-year analysis.

Figures 17 and 18 show that the climate trend-regressed anomalies calculated using the UDEL observations for the 30-year and 109-year periods compare well for both seasons. The climate trend contributions to temperature and precipitation changes are quite significant. The trend effect is more 
pronounced in summer, peaking at $-0.6 \mathrm{~K}$ and $-0.5 \mathrm{~mm} /$ day for temperature and precipitation, respectively.

These results give us an estimate of the statistical uncertainty in observations, confirming that it is acceptably small, and demonstrate that the 30 -year period is sufficient to draw reliable statistical conclusions, which we extend to the 30 -year model analysis.

\section{Acknowledgements}

The research reported in this publication was supported by the King Abdullah University of Science and Technology (KAUST). For computer time, this research used the resources of the Supercomputing Laboratory at KAUST in Thuwal, Saudi Arabia. The simulation results and supporting data sets are available from the corresponding author upon request. The UDEL observations and NCEP CFSR dataset used in this study is provided by the NOAA/OAR/ESRL PSD, Boulder, Colorado, USA, through their web site at http://www.esrl.noaa.gov/psd/

\section{References}

1. Abualnaja, Y., V. P. Papadopoulos, S. A. Josey, I. Hoteit, H. Kontoyiannis, and D. E. Raitsos (2015), Impacts of climate modes on air-sea heat exchange in the Red Sea, Journal of Climate, 28(7), 2665-2681.

2. Adams, J. B., M. E. Mann, and C. M. Ammann (2003), Proxy evidence for an El Nino-like response to volcanic forcing, Nature, 426(6964), 274-278.

3. Aiki, H., K. Takahashi, and T. Yamagata (2006), The Red Sea outflow regulated by the Indian monsoon, Continental Shelf Research, 26(12), 1448-1468.

4. Anchukaitis, K., B. Buckley, E. Cook, B. Cook, R. D'Arrigo, and C. Ammann (2010), Influence of volcanic eruptions on the climate of the Asian monsoon region, Geophysical Research Letters, 37(22), doi:10.1029/2010GL044843.

5. Anderson, J. L., V. Balaji, A. J. Broccoli, and W. F. Cooke (2004), The new GFDL global atmosphere and land model AM2-LM2: Evaluation with prescribed SST simulations, Journal of Climate, 17(24), 4641.

6. Ashok, K., Z. Guan, N. Saji, and T. Yamagata (2004), Individual and combined influences of ENSO and the Indian Ocean dipole on the Indian summer monsoon, Journal of Climate, 17(16), 3141-3155.

7. Ashok, K., S. K. Behera, S. A. Rao, H. Weng, and T. Yamagata (2007), El Niño Modoki and its possible teleconnection, Journal of Geophysical Research: Oceans, 112(C11), doi:10.1029/2006JC003798.

8. Atwater, M. A. (1970), Planetary albedo changes due to aerosols, Science, 170(3953), 64-66.

9. Bala, G., P. Duffy, and K. Taylor (2008), Impact of geoengineering schemes on the global hydrological cycle, Proceedings of the National Academy of Sciences, 105(22), 7664-7669.

10. Baldwin, M. P., and T. J. Dunkerton (1999), Propagation of the Arctic Oscillation from the stratosphere to the troposphere, Journal of Geophysical Research, 104(No. D24), 3093730946.

11. Bangalath, H and G. Stenchikov, (2015), Role of dust direct radiative effect on the tropical rain belt over Middle East and North Africa: A high-resolution AGCM study, J. Geophys. Res. Atmos., 120, doi:10.1002/2015JD023122.

12. Bretherton, C. S., J. R. McCaa, and H. Grenier (2004), A new parameterization for shallow 
cumulus convection and its application to marine subtropical cloud-topped boundary layers. Part I: Description and 1D results, Monthly weather review, 132(4), 864-882.

13. Camberlin, P., B. Fontaine, S. Louvet, P. Oettli, and P. Valimba (2010), Climate adjustments over Africa accompanying the Indian monsoon onset, Journal of Climate, 23(8), 2047-2064.

14. Crutzen, P. J. (2006), Albedo enhancement by stratospheric sulfur injections: a contribution to resolve a policy dilemma?, Climatic change, 77(3), 211-220.

15. Cullen, H. M., A. Kaplan, P. A. Arkin, and P. B. Demenocal (2002), Impact of the North Atlantic Oscillation on Middle Eastern climate and streamflow, Climatic Change, 55(3), 315338.

16. Driscoll, S., A. Bozzo, L. J. Gray, A. Robock, and G. Stenchikov (2012), Coupled Model Intercomparison Project 5 (CMIP5) simulations of climate following volcanic eruptions, Journal of Geophysical Research: Atmospheres, 117(D17).

17. Dogar, M. M., F. Kucharski, and S. Azharuddin (2017), Study of the global and regional climatic impacts of ENSO magnitude using SPEEDY AGCM, Journal of Earth System Science, 126(2), 30, doi:10.1007/s12040-017-0804-4.

18. Efron, B., and R. J. Tibshirani (1994), An introduction to the bootstrap, CRC press.

19. Emile-Geay, J., R. Seager, M. A. Cane, E. R. Cook, and G. H. Haug (2008), Volcanoes and ENSO over the past millennium, Journal of Climate, 21(13), 3134-3148.

20. Fischer, E. M., J. Luterbacher, E. Zorita, S. F. B. Tett, C. Casty, and Wanner H. (2007), European climate response to tropical volcanic eruptions over the last half millennium, Geophysical Research Letters, 34(L05707), doi:10.1029/2006GL027992.

21. Flaounas, E., S. Janicot, S. Bastin, R. Roca, and E. Mohino (2012), The role of the Indian monsoon onset in the West African monsoon onset: observations and AGCM nudged simulations, Climate dynamics, 38(5-6), 965-983.

22. Franklin, B. (1784), Meteorological imaginations and conjectures. , Mem. Proc. Lit. Philos. Soc., 2, 357-361.

23. Freidenreich, S. M., and V. Ramaswamy, (1999), A new multiple-band solar radiative parameterization for general circulation models. J. Geophys. Res., 104, 31389-31409.

24. Fujiwara, M., T. Hibino, S. Mehta, L. Gray, D. Mitchell, and J. Anstey (2015), Global temperature response to the major volcanic eruptions in multiple reanalysis data sets, Atmospheric chemistry and physics, 15(23), 13507-13518.

25. Fyfe, J., K. Salzen, J. Cole, N. Gillett, and J. P. Vernier (2013), Surface response to stratospheric aerosol changes in a coupled atmosphere-ocean model, Geophysical Research Letters, 40(3), 584-588.

26. Genin, A., B. Lazar, and S. Brenner (1995), Vertical mixing and coral death in the Red Sea following the eruption of Mount Pinatubo, Nature, 377(6549), 507.

27. Graf, H.-F. (1992), Arctic radiation deficit and climate variability, Climate Dynamics, 7(1), 19-28.

28. Graf, H.-F., I. Kirchner, A. Robock, and I. Schult (1993), Pinatubo eruption winter climate effects: model versus observations, Climate Dynamics(9), 81-93.

29. Graf, H.-F., J. Perlwitz, and I. Kirchner (1994), Northern hemisphere tropospheric midlatitude circulation after violent volcanic eruptions, Contributions to atmospheric physics, 67(1), 3-13.

30. Groisman, P. Y. (1992), Possible regional climate consequences of the Pinatubo eruption: An empirical approach, Geophys. Res. Lett., 19, $1603-1606$.

31. Gujarati, D. N. (2009), Basic econometrics, Tata McGraw-Hill Education.

32. Hansen, J., D. Johnson, A. Lacis, S. Lebedeff, P. Lee, D. Rind, and G. Russell (1981), Climate impact of increasing atmospheric carbon dioxide, Science, 213(4511), 957-966.

33. Hansen, J., A. Lacis, R. Ruedy, and M. Sato (1992), Potential climate impact of Mount Pinatubo eruption, Geophysical Research Letters, 19, 215-218.

34. Hatzianastassiou, N., C. Matsoukas, E. Drakakis, P. Stackhouse Jr, P. Koepke, A. Fotiadi, K. Pavlakis, and I. Vardavas (2007), The direct effect of aerosols on solar radiation based on satellite observations, reanalysis datasets, and spectral aerosol optical properties from Global Aerosol Data Set (GADS), Atmospheric Chemistry and Physics, 7(10), 2585-2599.

35. Haywood, J. M., A. Jones, N. Bellouin, and D. and Stephenson (2013), Asymmetric forcing 
from stratospheric aerosols impacts Sahelian rainfall, Nature Climate Change, 3, 660-665, doi:10.1038/nclimate1857.

36. Horowitz, L. W., S. Walters, D. L. Mauzerall, L. K. Emmons, P. J. Rasch, C. Granier, X. Tie, J. F. Lamarque, M. G. Schultz, and G. S. Tyndall (2003), A global simulation of tropospheric ozone and related tracers: Description and evaluation of MOZART, version 2, Journal of Geophysical Research: Atmospheres, 108(D24).

37. Hurrell, J. W., and C. Deser (2010), North Atlantic climate variability: the role of the North Atlantic Oscillation, Journal of Marine Systems, 79(3), 231-244.

38. Hurrell, J. W. (1995), Decadal trends in the North Atlantic Oscillation: regional temperatures and precipitation, Science, 269(5224), 676-679.

39. Iqbal, M., S. Hameed, and F. Khan (2013), Influence of Azores high pressure on Middle Eastern rainfall, Theoretical and applied climatology, 111(1-2), 211-221.

40. Joseph, R., and N. Zeng (2011), Seasonally modulated tropical drought induced by volcanic aerosol, Journal of Climate, 24(8), 2045-2060.

41. Josey, S. A., S. Somot, and M. Tsimplis (2011), Impacts of atmospheric modes of variability on Mediterranean Sea surface heat exchange, Journal of Geophysical Research: Oceans, 116(C2).

42. Kelly, P. M., P. Jones and P. Jia (1996), The spatial response of the climate system to explosive volcanic eruptions, International Journal of Climatology, 16(5), 537-550.

43. Kirchner, I., G. L. Stenchikov, H. F. Graf, A. Robock, and J. C. Antuña (1999), Climate model simulation of winter warming and summer cooling following the 1991 Mount Pinatubo volcanic eruption, Journal of Geophysical Research: Atmospheres, 104(D16), 19039-19055.

44. Kremser, S., et al. (2016), Stratospheric aerosol-Observations, processes, and impact on climate, Rev. Geophys., 54, doi:10.1002/2015RG000511.

45. Krichak, S., P. Kishcha, and P. Alpert (2002), Decadal trends of main Eurasian oscillations and the Eastern Mediterranean precipitation, Theoretical and Applied Climatology, 72(3-4), 209-220.

46. Kodera, K. (1994), Influence of volcanic eruptions on the troposphere through stratospheric dynamical processes in the Northern Hemisphere winter, J. Geophys. Res., 99, 1273-1282.

47. Kodera, K., and M. Chiba (1995), Tropospheric circulation changes associated with stratospheric sudden warmings: A case study, Journal of Geophysical Research: Atmospheres, 100(D6), 11055-11068.

48. Laakso, A., H. Kokkola, A. I. Partanen, U. Niemeier, C. Timmreck, K. E. J. Lehtinen, H. Hakkarainen, and H. Korhonen (2016), Radiative and climate impacts of a large volcanic eruption during stratospheric sulfur geoengineering, Atmos. Chem. Phys., 16(1), 305-323, doi:10.5194/acp-16-305-2016.

49. Lamb, H. H. (1970), Volcanic dust in the atmosphere; with a chronology and assessment of its meteorological significance, Philosophical Transactions of the Royal Society of London. Series A, Mathematical and Physical Sciences, 266(1178), 425-533.

50. Legates, D. R., and C. J. Willmott (1990), Mean seasonal and spatial variability in gaugecorrected, global precipitation, International Journal of Climatology, 10(2), 111-127.

51. Lim, Y.-K. (2015), The East Atlantic/West Russia (EA/WR) teleconnection in the North Atlantic: climate impact and relation to Rossby wave propagation, Climate Dynamics, 44(1112), 3211-3222.

52. Liu, F., J. Chai, B. Wang, J. Liu, X. Zhang, and Z. Wang (2016), Global monsoon precipitation responses to large volcanic eruptions, Scientific reports, 6 .

53. Maher, N., S. McGregor, M. H. England, and A. S. Gupta (2015), Effects of volcanism on tropical variability, Geophysical Research Letters, 42(14), 6024-6033.

54. McCracken, M., and F. Luther (1984), Preliminary estimate of the radiative and climatic effects of the El Chichón eruption Geofis. Int., 23-3,385-401.

55. Malyshev, Sergey, Elena Shevliakova, Ronald J Stouffer, and S W Pacala, 2015: Contrasting Local vs. Regional Effects of Land-Use-Change Induced Heterogeneity on Historical Climate: Analysis with the GFDL Earth System Model. Journal of Climate, 28(13), DOI:10.1175/JCLI-D-14-00586.1 
56. Mann, M. E., M. A. Cane, S. E. Zebiak, and A. Clement (2005), Volcanic and solar forcing of the tropical Pacific over the past 1000 years, Journal of Climate, 18(3), 447-456.

57. Man, W., T. Zhou, and J. H. Jungclaus (2014), Effects of large volcanic eruptions on global summer climate and East Asian monsoon changes during the last millennium: Analysis of MPI-ESM simulations, Journal of Climate, 27(19), 7394-7409.

58. Mass, C. F., \& Portman, D. A. (1989). Major volcanic eruptions and climate: A critical evaluation. Journal of Climate, 2(6), 566-593.

59. Minnis, P., E. Harrison, L. Stowe, G. Gibson, F. Denn, D. Doelling, and W. Smith (1993), Radiative climate forcing by the Mount Pinatubo eruption, Science, 259(5100), 1411-1415.

60. Mitchell, J. M. (1961), Recent secular changes of global temperature, Annals of the New York Academy of Sciences, 95(1), 235-250.

61. Mitchell Jr, J. M. (1971), The effect of atmospheric aerosols on climate with special reference to temperature near the earth's surface, Journal of Applied Meteorology, 10(4), 703-714.

62. Moorthi, S., and M. J. Suarez (1992), Relaxed Arakawa-Schubert. A parameterization of moist convection for general circulation models, Monthly Weather Review, 120(6), 9781002.

63. Ohba, M., H. Shiogama, T. Yokohata, and M. Watanabe (2013), Impact of strong tropical volcanic eruptions on ENSO simulated in a coupled GCM, J. Clim., 26, 5169-5182.

64. Oman, L., A. Robock, G. Stenchikov, G. A. Schmidt, and R. Ruedy (2005), Climatic response to high-latitude volcanic eruptions, Journal of Geophysical Research, 110(D13103), doi:10.1029/2004JD005487.

65. Oman, L., A. Robock, G. L. Stenchikov, and T. Thordarson (2006), High-latitude eruptions cast shadow over the African monsoon and the flow of the Nile, Geophysical Research Letters, 33, doi:10.1029/2006GL027665.

66. Otterå, O. (2008), Simulating the effects of the 1991 Mount Pinatubo volcanic eruption using the ARPEGE atmosphere general circulation model, Adv. Atmos. Sci., 25, 213-226, doi:10.1007/s00376-008-0213-3.

67. Papadopoulos, V. P., Abualnaja, Y., Josey, S. A., Bower, A., Raitsos, D. E., Kontoyiannis, H., \& Hoteit, I. (2013). Atmospheric forcing of the winter air-sea heat fluxes over the northern Red Sea. Journal of Climate, 26(5), 1685-1701.

68. Pausata, F. S., L. Chafik, R. Caballero, and D. S. Battisti (2015), Impacts of high-latitude volcanic eruptions on ENSO and AMOC, Proceedings of the National Academy of Sciences, 112(45), 13784-13788.

69. Pausata, F. S., A. Grini, R. Caballero, A. Hannachi, and $\varnothing$. Seland (2015), High-latitude volcanic eruptions in the Norwegian Earth System Model: the effect of different initial conditions and of the ensemble size, Tellus B, 67.

70. Pausata, F. S., C. Karamperidou, R. Caballero, and D. S. Battisti (2016), ENSO response to high-latitude volcanic eruptions in the Northern Hemisphere: The role of the initial conditions, Geophysical Research Letters, 43(16), 8694-8702.

71. Peng, Y., C. Shen, W.-C. Wang, and Y. Xu (2010), Response of summer precipitation over Eastern China to large volcanic eruptions, Journal of Climate, 23(3), 818-824.

72. Penner, A., and J. Binyamin (2013), Climate Change Associated with Global Teleconnections, Volcanic Eruptions, and the Arctic's Snow-Ice Albedo in Godthab, Greenland, doi:http://dx.doi.org/10.4236/acs.2013.31005.

73. Parthasarathy, B. Monthly and seasonal rainfall series for All-India homogeneous regions and meteorological subdivisions, 1871-1994. Indian Institute of Tropical Meteorology, 1995.

74. Parthasarathy, B., A. Munot, and D. Kothawale (1994), All-India monthly and seasonal rainfall series: 1871-1993, Theoretical and Applied Climatology, 49(4), 217-224.

75. Portman, D. A., and D. S. Gutzler (1996), Explosive volcanic eruptions, the El Niño-Southern Oscillation, and US climate variability, Journal of climate, 9(1), 17-33.

76. Predybaylo, E., G. Stenchikov, A. Wittenberg, F. Zeng, 2017: Impact of a Pinatubo-Size Volcanic Eruption on ENSO, J. Geophys. Res. Atmos., 122, 925-947, doi:10.1002/2016JD025796.

77. Putman, W. M., and S.-J. Lin (2007), Finite-volume transport on various cubed-sphere grids, J. Comput. Phys., 227, 55-78, doi:10.1016/j.jcp.2007.07.022. 
78. Ramachandran, S., V. Ramaswamy, G. L. Stenchikov, and A. Robock (2000), Radiative impact of the Mount Pinatubo volcanic eruption: Lower stratospheric response, Journal of Geophysical Research: Atmospheres (1984-2012), 105(D19), 24409-24429.

79. Randel, W. J. (2010), Variability and trends in stratospheric temperature and water vapor, The Stratosphere: Dynamics, Transport and Chemistry, 60th.

80. Rayner, N., D. E. Parker, E. Horton, C. Folland, L. Alexander, D. Rowell, E. Kent, and A. Kaplan (2003), Global analyses of sea surface temperature, sea ice, and night marine air temperature since the late nineteenth century, J. Geophys. Res., 108(D14), 4407, doi:10.1029/2002JD002670. Roberts, D. L., and A. Jones (2004), Climate sensitivity to black carbon aerosol from fossil fuel combustion, J. Geophys. Res., 109, D16202, doi:10.1029/2004JD004676.

81. Rind, D., J. Perlwitz, and P. Lonergan (2005), AO/NAO response to climate change: 1. Respective influences of stratospheric and tropospheric climate changes, Journal of Geophysical Research: Atmospheres (1984-2012), 110(D12).

82. Robock, A., and J. Mao (1992), Winter warming from large volcanic eruptions, Geophysical Research Letters, 19(24), 2405-2408.

83. Robock, A., and Y. Liu (1994), The volcanic signal in Goddard Institute for Space Studies three-dimensional model simulations, Journal of Climate, 7(1), 44-55.

84. Robock, A., and J. Mao (1995), The volcanic signal in surface temperature observations, Journal of Climate, 8(5), 1086-1103.

85. Robock, A. (2000), Volcanic eruption and Climate. Reviews of Geophysics 38,2, 191-219.

86. Robock, A. (2001), Stratospheric forcing needed for dynamical seasonal prediction, Bulletin of the American Meteorological Society, 82(10), 2189-2192.

87. Robock, A. (2002), The climatic aftermath, Science, 295(5558), 1242-1244.

88. Rodwell, M. J., and B. J. Hoskins (1996), Monsoons and the dynamics of deserts, Quarterly Journal of the Royal Meteorological Society, 122(534), 1385-1404.

89. Saha, S., S. Moorthi, H.-L. Pan, X. Wu, J. Wang, S. Nadiga, P. Tripp, R. Kistler, J. Woollen, and D. Behringer (2010), The NCEP climate forecast system reanalysis, Bulletin of the American Meteorological Society, 91(8), 1015-1057.

90. Santer, B. D., et al. (2001), Accounting for the effect of volcanoes and ENSO in comparisons of modeled and observed temperature trends, J. Geophys. Res., 106, 28,033-28,059, doi:10.1029/2000JD000189.

91. Santer, B. D., C. Bonfils, J. F. Painter, M. D. Zelinka, C. Mears, S. Solomon, G. A. Schmidt, J. C. Fyfe, J. N. Cole, and L. Nazarenko (2014), Volcanic contribution to decadal changes in tropospheric temperature, Nature Geoscience, 7(3), 185-189.

92. Sato, M., J. E. Hansen, M. P. McCormick, and J. B. Pollack (1993), Stratospheric aerosol optical depths, 1850-1990, Journal of Geophysical Research: Atmospheres, 98(D12), 2298722994.

93. Schmidt, H., K. Alterskjær, D. Bou Karam, O. Boucher, A. Jones, J. Kristjánsson, U. Niemeier, M. Schulz, A. Aaheim, and F. Benduhn (2012), Solar irradiance reduction to counteract radiative forcing from a quadrupling of $\mathrm{CO} 2$ : climate responses simulated by four earth system models, Earth System Dynamics, 3, 63-78.

94. Schwarzkopf, M. D., and V. Ramaswamy (1999), Radiative effects of CH4, N2O, halocarbons and the foreign- broadened $\mathrm{H} 2 \mathrm{O}$ continuum: A GCM experiment, Journal of Geophysical Research: Atmospheres (1984-2012), 104(D8), 9467-9488.

95. Schneider, D. P., C. M. Ammann, B. L. Otto-Bliesner, and D. S. Kaufman (2009), Climate response to large, high-latitude and low-latitude volcanic eruptions in the Community Climate System Model, Journal of Geophysical Research: Atmospheres (1984-2012), 114(D15).

96. Shindell, D. T., G. A. Schmidt, R. L. Miller, and D. Rind (2001), Northern Hemisphere winter climate response to greenhouse gas, ozone, solar, and volcanic forcing, Journal of Geophysical Research: Atmospheres (1984-2012), 106(D7), 7193-7210.

97. Shindell, D. T., G. A. Schmidt, M. E. Mann, and G. Faluvegi (2004), Dynamic winter climate response to large tropical volcanic eruptions since 1600, Journal of Geophysical Research: Atmospheres, 109(D5).

98. Shukla, J. (1975), Effect of Arabian sea-surface temperature anomaly on Indian summer 
monsoon: A numerical experiment with the GFDL model, Journal of the Atmospheric Sciences, 32(3), 503-511.

99. Sigurdsson, H. (1982), Volcanic pollution and climate: the 1783 Laki eruption, Eos, Transactions American Geophysical Union, 63(32), 601-602.

100. Simpson, I. R., R. Seager, T. A. Shaw, and M. Ting (2015), Mediterranean summer climate and the importance of Middle East topography, Journal of Climate, 28(5), 1977-1996.

101. Soden, B. J., Wetherald, R. T., Stenchikov, G. L., \& Robock, A. (2002). Global cooling after the eruption of Mount Pinatubo: A test of climate feedback by water vapor. Science, 296(5568), 727-730.

102. Stenchikov, G. L., I. Kirchner, A. Robock, H. F. Graf, J. C. Antuna, R. Grainger, A. Lambert, and L. Thomason (1998), Radiative forcing from the 1991 Mount Pinatubo volcanic eruption, Journal of Geophysical Research: Atmospheres (1984-2012), 103(D12), 13837-13857.

103. Stenchikov, G., K. Hamilton, R. J. Stouffer, A. Robock, V. Ramaswamy, B. Santer, and H. F. Graf (2006), Arctic Oscillation response to volcanic eruptions in the IPCC AR4 climate models, Journal of Geophysical Research: Atmospheres (1984-2012), 111(D7).

104. Stenchikov, G., A. Robock, V. Ramaswamy, M. D. Schwarzkopf, K. Hamilton, and S. Ramachandran (2002), Arctic Oscillation response to the 1991 Mount Pinatubo eruption: Effects of volcanic aerosols and ozone depletion. Journal of Geophysical Research, 107(D24). doi: 10.1029/2002JD002090.

105. Stenchikov, G., T. L. Delworth, V. Ramaswamy, R. J. Stouffer, A. Wittenberg, and F. Zeng (2009), Volcanic signals in oceans, Journal of Geophysical Research, 114(D16104), doi:10.1029/2008JD011673.

106. Stenchikov, G. (2009), Chapter 4-The role of volcanic activity in climate and global change, in Climate Change: Observed Impacts on Planet, edited by T. M. Letcher, pp. 77-102, Elsevier, Amsterdam.

107. Sultan, B., and S. Janicot (2000), Abrupt shift of the ITCZ over West Africa and intra-seosnal variability, Geophysical Research Letters, 27(20), 3353-3356, doi:10.1029/1999GL011285.

108. Tandon, N. F., E. P. Gerber, A. H. Sobel, and L. M. Polvani (2013), Understanding Hadley cell expansion versus contraction: Insights from simplified models and implications for recent observations, Journal of Climate, 26(12), 4304-4321.

109. Thompson, D. W., and J. M. Wallace (1998), The Arctic Oscillation signature in the wintertime geopotential height and temperature fields, Geophysical Research Letters, 25(9), 1297-1300.

110. Thompson, D. W., and J. M. Wallace (2000), Annular modes in the extratropical circulation. Part I: month-to-month variability*, Journal of Climate, 13(5), 1000-1016.

111. Timmreck, C. (2012), Modeling the climatic effects of large explosive volcanic eruptions. WIREs Clim Change, 3: 545-564. doi: 10.1002/wcc.192

112. Timmermann, A., J. Oberhuber, A. Bacher, M. Esch, M. Latif, and E. Roeckner (1999), Increased El Niño frequency in a climate model forced by future greenhouse warming, Nature, 398(6729), 694-697.

113. Trenberth, K. E., G. W. Branstator, D. Karoly, A. Kumar, N. C. Lau, and C. Ropelewski (1998), Progress during TOGA in understanding and modeling global teleconnections associated with tropical sea surface temperatures, Journal of Geophysical Research: Oceans, 103(C7), 14291-14324.

114. Trenberth, K. E., and J. M. Caron (2000), The Southern Oscillation revisited: Sea level pressures, surface temperatures, and precipitation, Journal of Climate, 13(24), 4358-4365.

115. Trenberth, K. E., and A. Dai (2007), Effects of Mount Pinatubo volcanic eruption on the hydrological cycle as an analog of geoengineering, Geophysical Research Letters, 34, L15702, doi:10.1029/2007GL030524.

116. Turco, R., R. Whitten, and O. Toon (1982), Stratospheric aerosols: Observation and theory, Copyright 2000 by the American Geophysical Union, 20(2), 233-279.

117. van Loon, H., and J. C. Rogers (1978), The seesaw in winter temperatures between Greenland and northern Europe. Part I: General description, Monthly Weather Review, 106(3), 296-310.

118. Wild, M., J. Grieser, and C. Schär (2008), Combined surface solar brightening and increasing greenhouse effect support recent intensification of the global land-based hydrological cycle, 
Geophysical Research Letters, 35(17).

119. Wallace, J. M., and D. S. Gutzler (1981), Teleconnections in the geopotential height field during the Northern Hemisphere winter, Monthly Weather Review, 109(4), 784-812.

120. Wegmann, M., S. Brönnimann, J. Bhend, J. Franke, D. Folini, M. Wild, and J. Luterbacher (2014), Volcanic Influence on European Summer Precipitation through Monsoons: Possible Cause for "Years without Summer"*, Journal of Climate, 27(10), 3683-3691.

121. Xu, K.-M. (2006), Using the bootstrap method for a statistical significance test of differences between summary histograms, Monthly weather review, 134(5), 1442-1453.

122. Yu, R., and T. Zhou (2004), Impacts of winter-NAO on March cooling trends over subtropical Eurasia continent in the recent half century, Geophysical Research Letters, 31(12), doi:10.1029/2004GL019814.

123. Zhao, M., I. M. Held, S.-J. Lin, and G. A. Vecchi (2009), Simulations of global hurricane climatology, interannual variability, and response to global warming using a 50-km resolution GCM, Journal of Climate, 22(24), 6653-6678.

124. Zhang, D., R. Blender, and K. Fraedrich (2013), Volcanoes and ENSO in millennium simulations: Global impacts and regional reconstructions in East Asia, Theoretical and applied climatology, 111(3-4), 437-454.

125. Zhang, W., F.-F. Jin, J.-X. Zhao, L. Qi, and H.-L. Ren (2013), The possible influence of a nonconventional El Niño on the severe autumn drought of 2009 in Southwest China, Journal of Climate, 26(21), 8392-8405.

126. Zhang, W., L. Wang, B. Xiang, L. Qi, and J. He (2015), Impacts of two types of La Niña on the NAO during boreal winter, Climate Dynamics, 44(5-6), 1351-1366.

127. Wanner, H., S. Brönnimann, C. Casty, D. Gyalistras, J. Luterbacher, C. Schmutz, D. B. Stephenson, and E. Xoplaki (2001), North Atlantic Oscillation-concepts and studies, Surveys in geophysics, 22(4), 321-381.

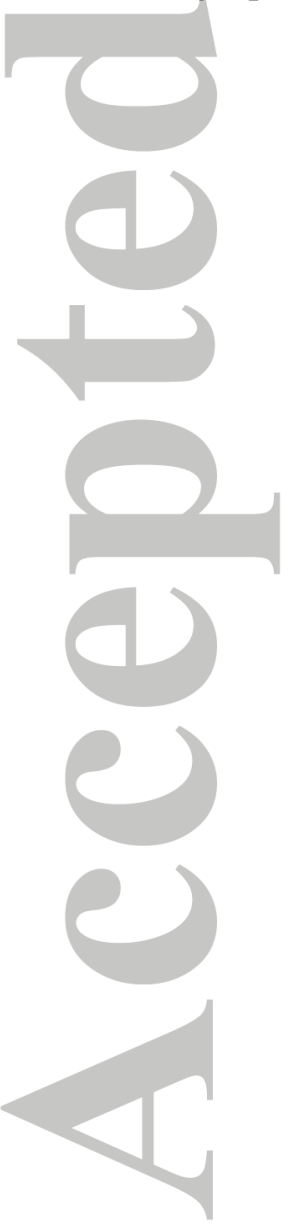




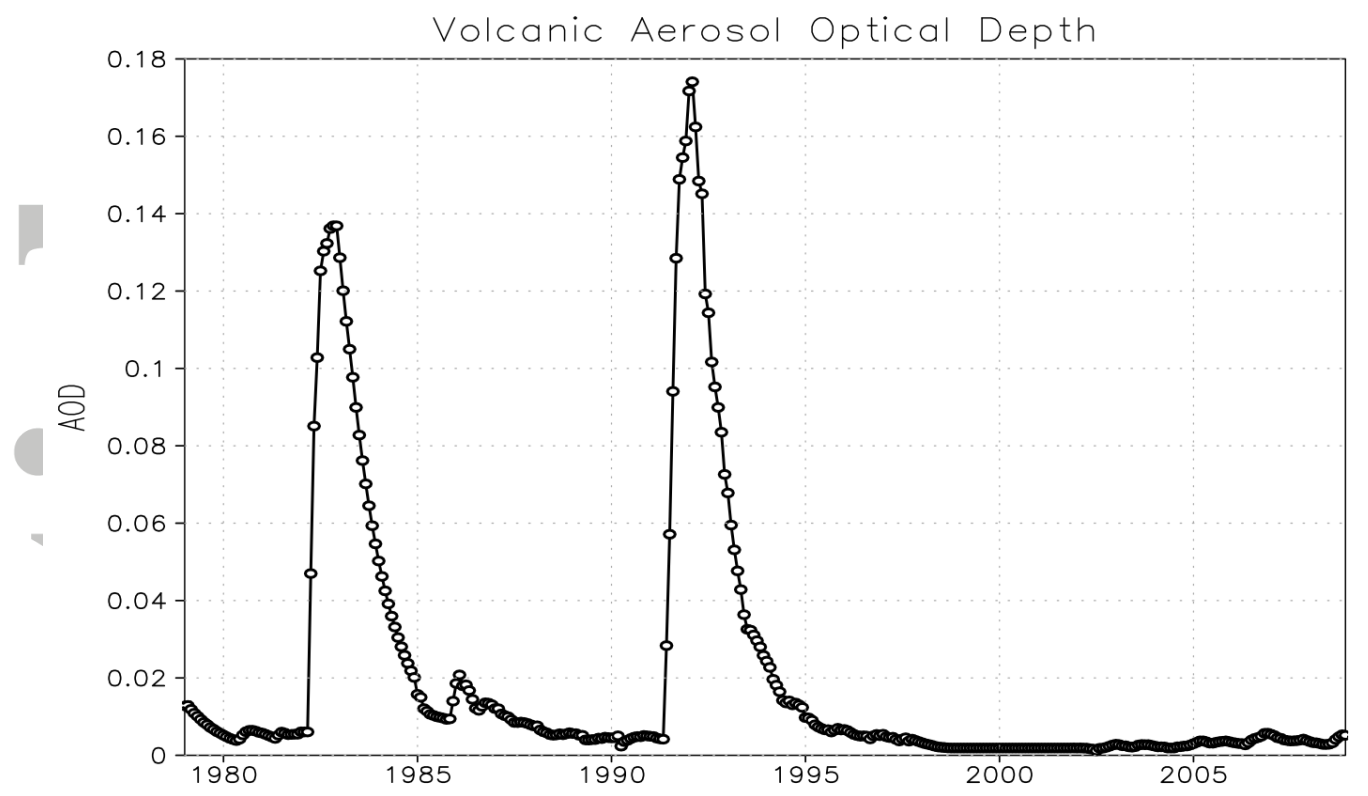

Figure 1: Total stratospheric aerosol optical depth at $550 \mathrm{~nm}$ from [Sato et al., 1993] as a function of time, zonally averaged over the MENA latitudes.

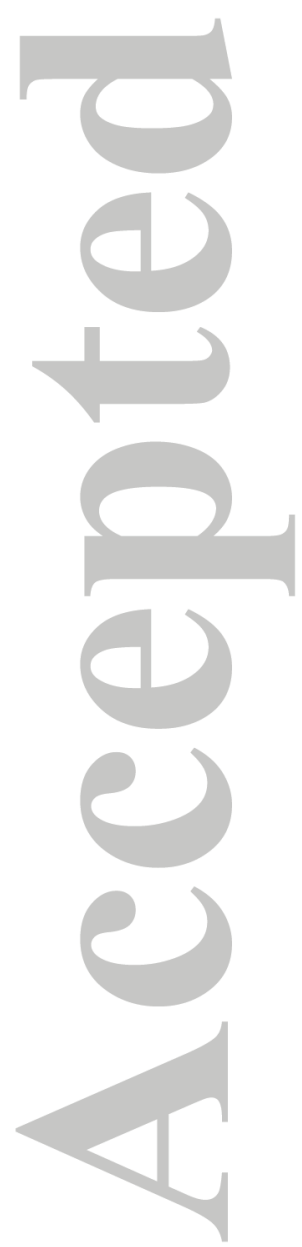



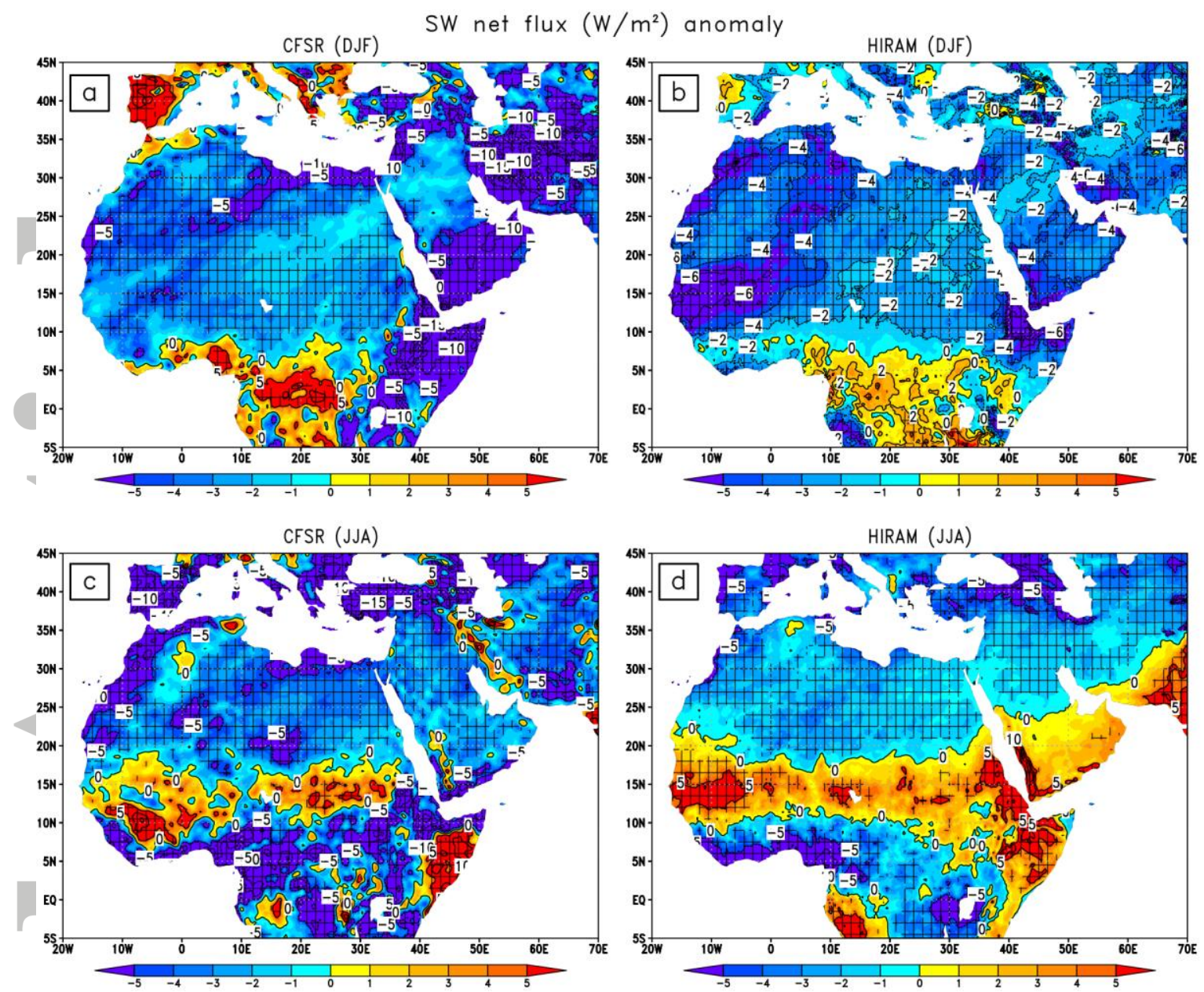

Figure 2: Seasonal (DJF and JJA) two-year anomalies of solar net flux $\left(\mathrm{W} / \mathrm{m}^{2}\right)$ composites following the El Chichón and Pinatubo eruptions, calculated for winter using a) CFSR and b) HiRAM outputs, and for summer using c) CFSR and d) HiRAM outputs. Hatching shows the statistically significant areas with at least $95 \%$ confidence level. 

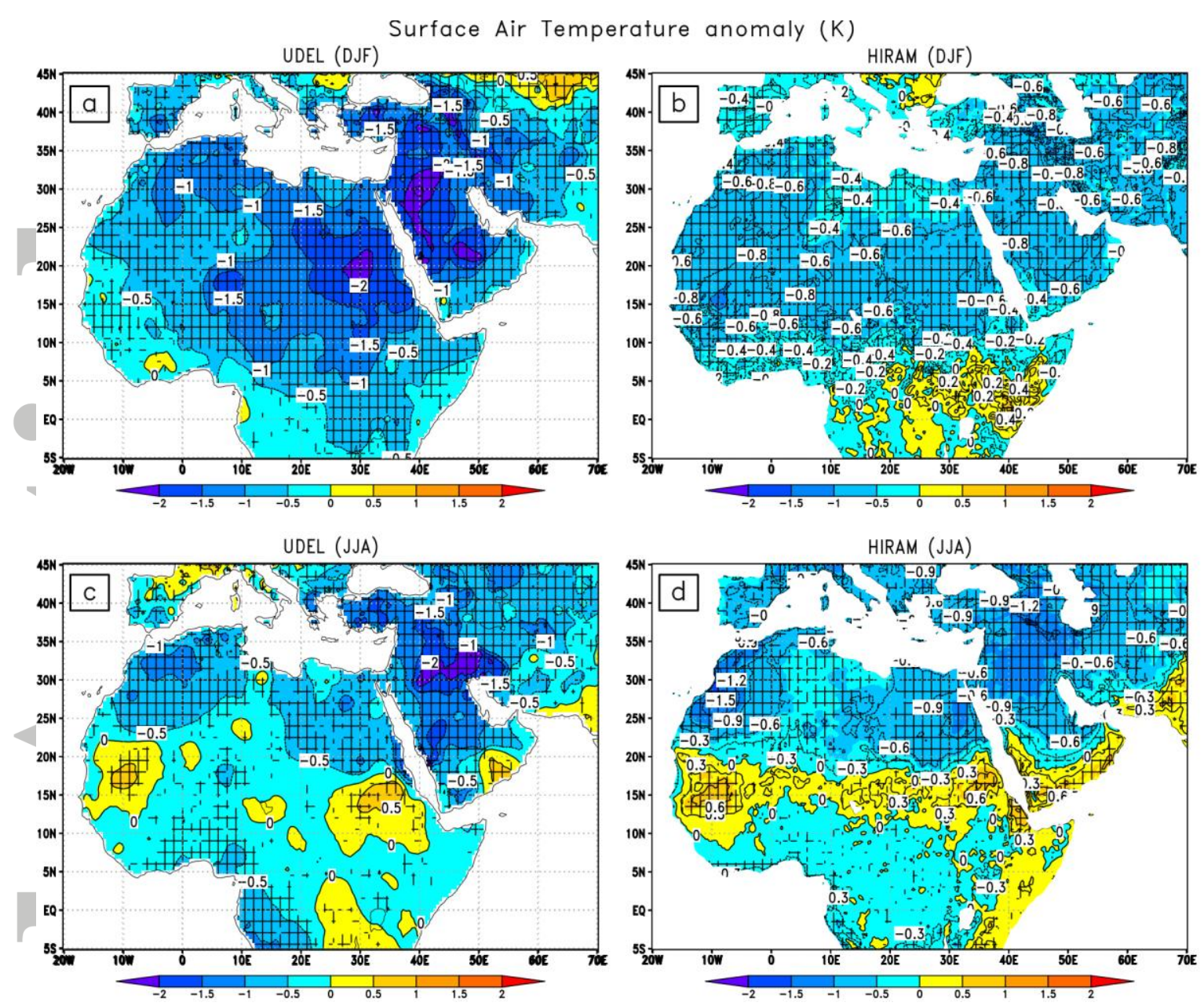

Figure 3: Seasonal (DJF and JJA) two-year anomalies of surface air temperature (K) composites following the El Chichón and Pinatubo eruptions, calculated for winter using a) UDEL observations, b) HiRAM output, and for summer using c) UDEL observations, d) HiRAM output. Hatching shows the statistically significant areas with at least $95 \%$ confidence level.

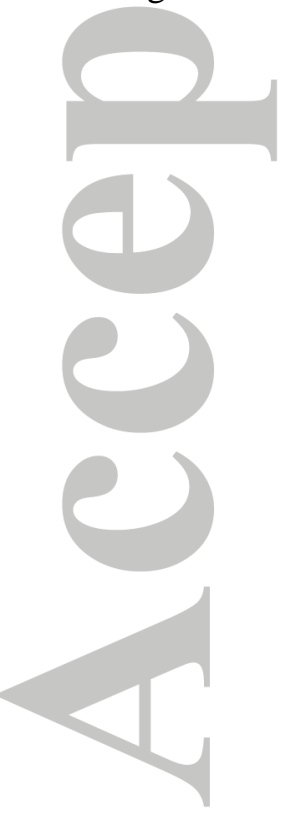



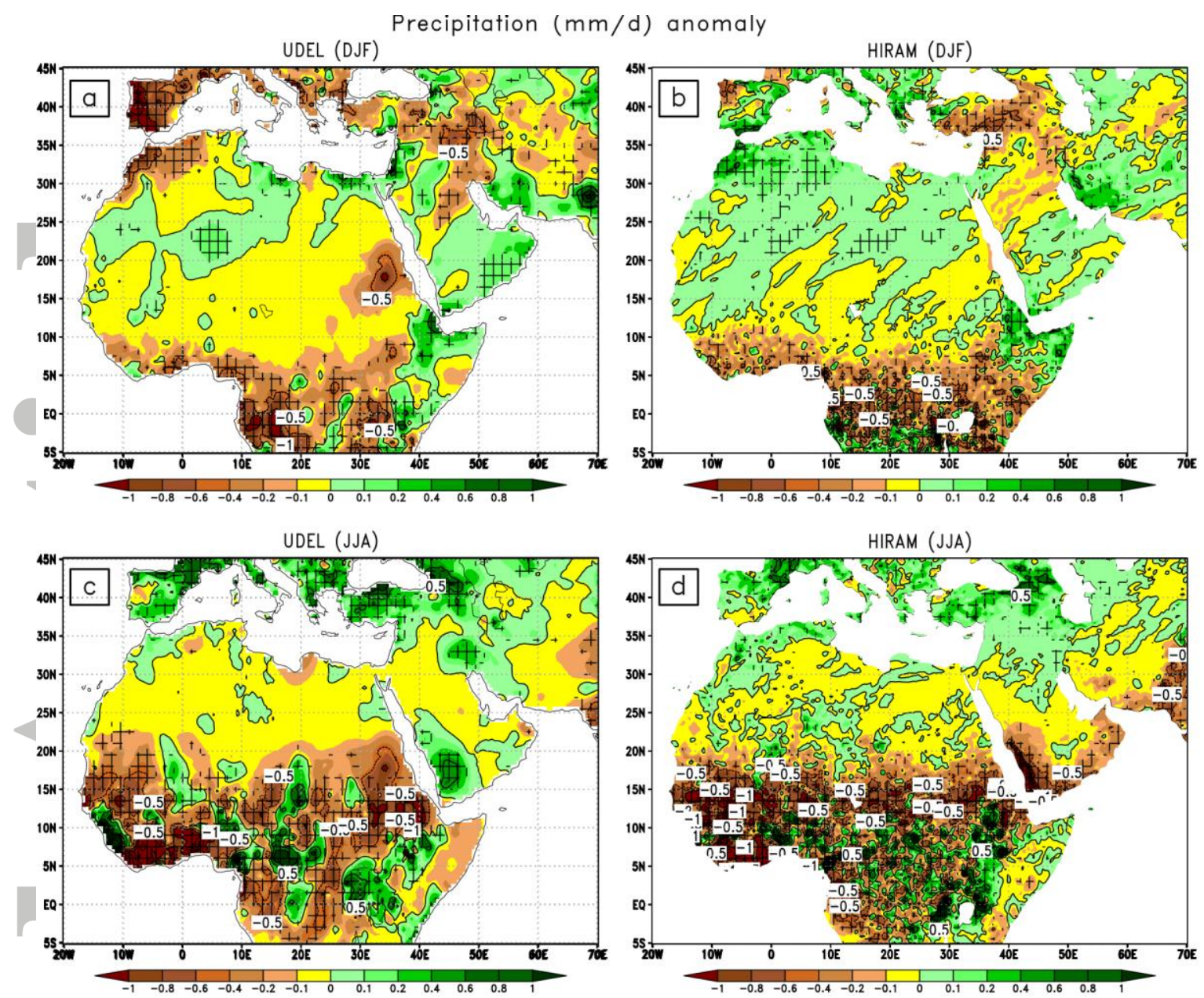

Figure 4: Same as Fig. 3, but for precipitation anomaly (mm/day). 
Hadley Vertical Mass Flux $\left(10^{-3} \mathrm{Kgm}^{-2} \mathrm{~s}^{-1}\right)$ at $500 \mathrm{hPa}$

CFSR JJA mean
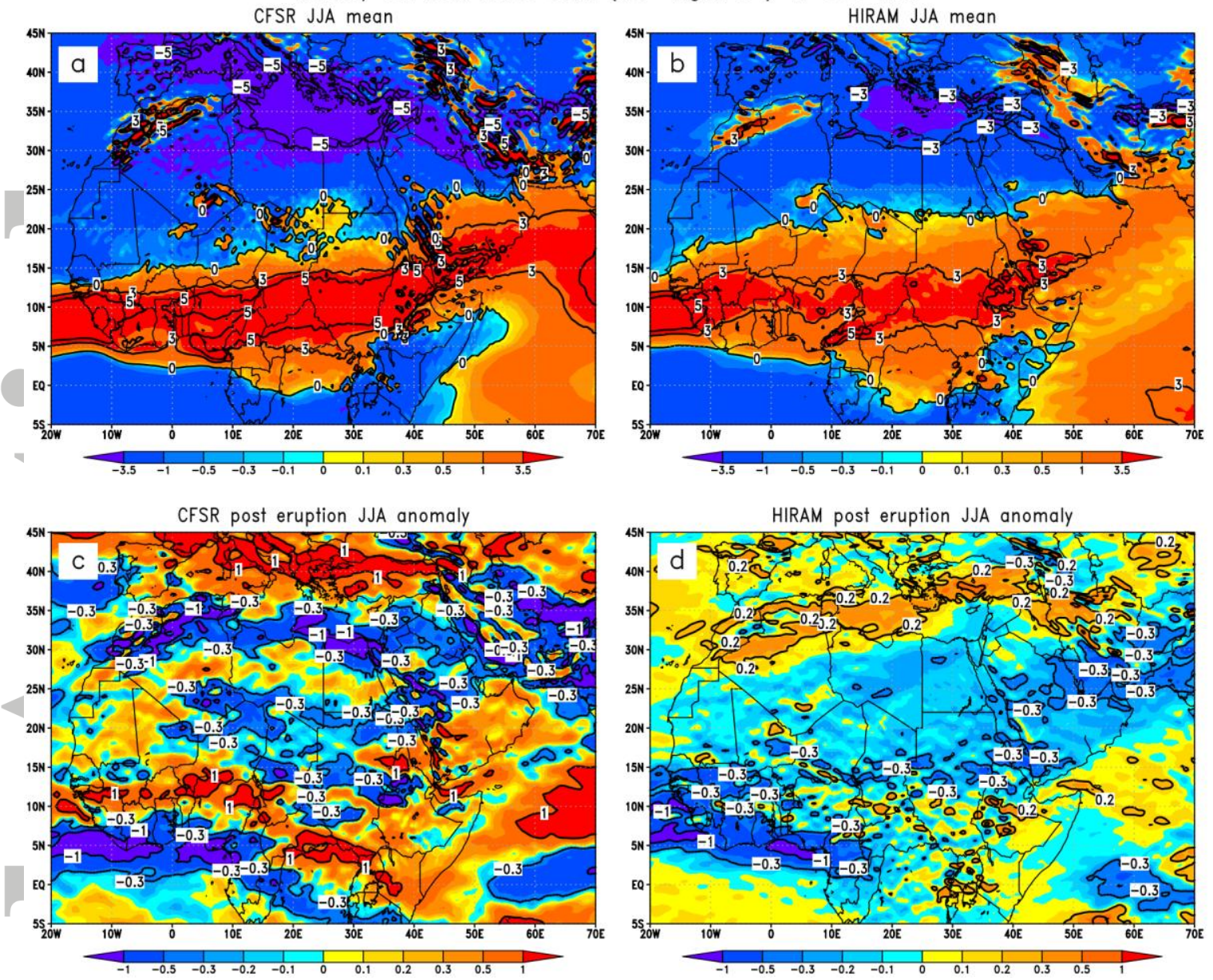

Figure 5: Summer (JJA) total vertical regional Hadley Cell mass flux $\mathrm{M}_{\Phi}$ (positive upward, $10^{-3} \mathrm{~kg}$ $\mathrm{m}^{-2} \mathrm{~s}^{-1}$ ) averaged over the 1979-2008 period (excluding post-eruption years) using a) CFSR, b) HiRAM outputs, and two-year composited anomalies of $\mathrm{M}_{\Phi}\left(10^{-3} \mathrm{~kg} \mathrm{~m}^{-2} \mathrm{~s}^{-1}\right)$ following the El Chichón and Pinatubo eruptions calculated using c) CFSR, d) HiRAM outputs.

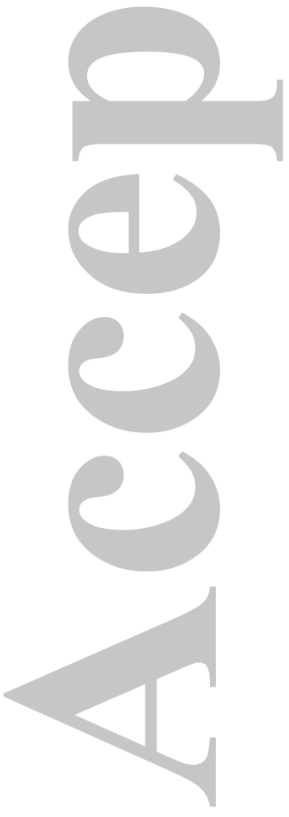

(c) 2017 American Geophysical Union. All rights reserved. 

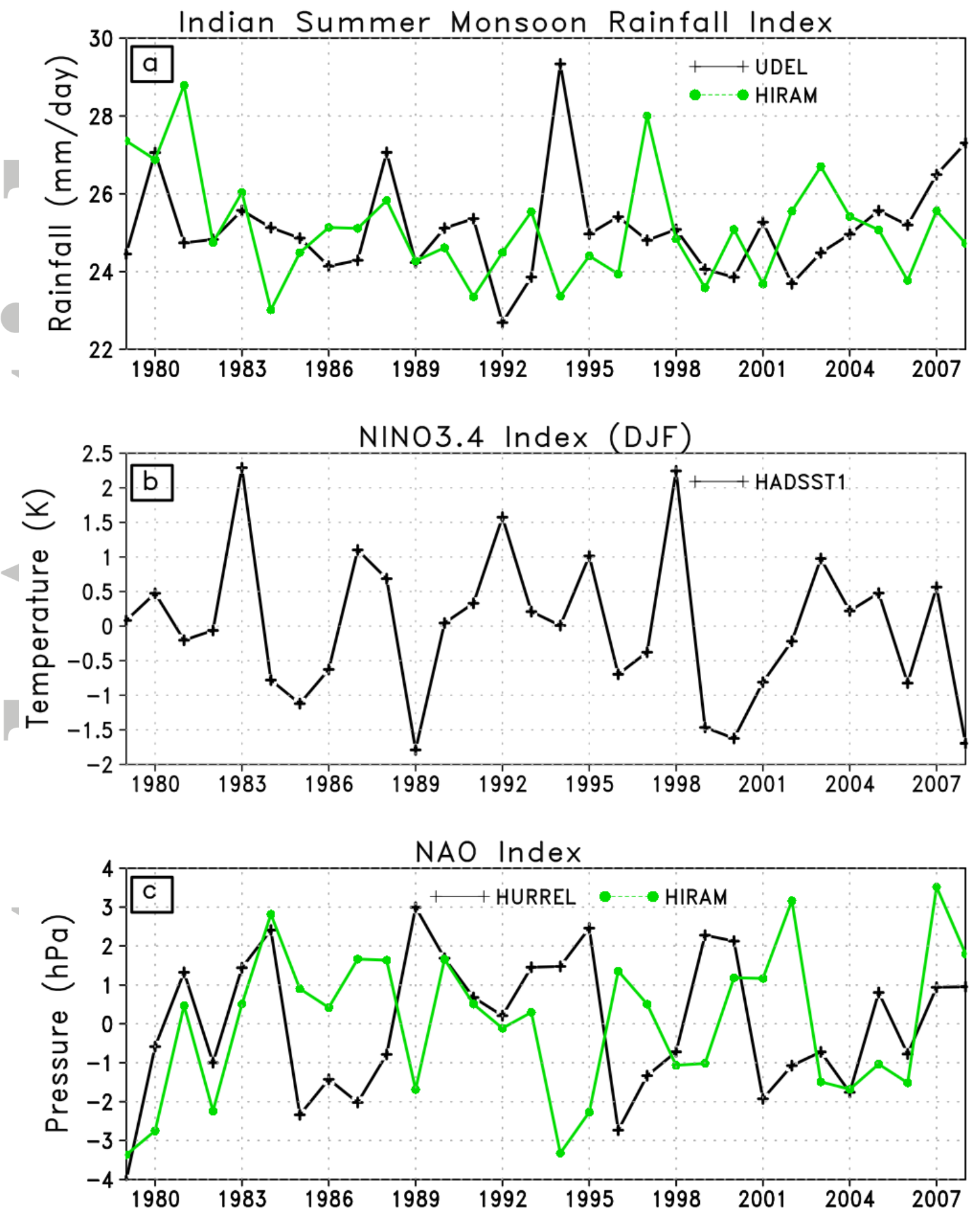

Figure 6: Time series of predictors (not standardized) from the observations and HiRAM used in the regression analysis in both seasons a) Indian Monsoon Rainfall Index, b) NINO3.4/DJF, c) NAO Index of Hurrell, [1995]. 

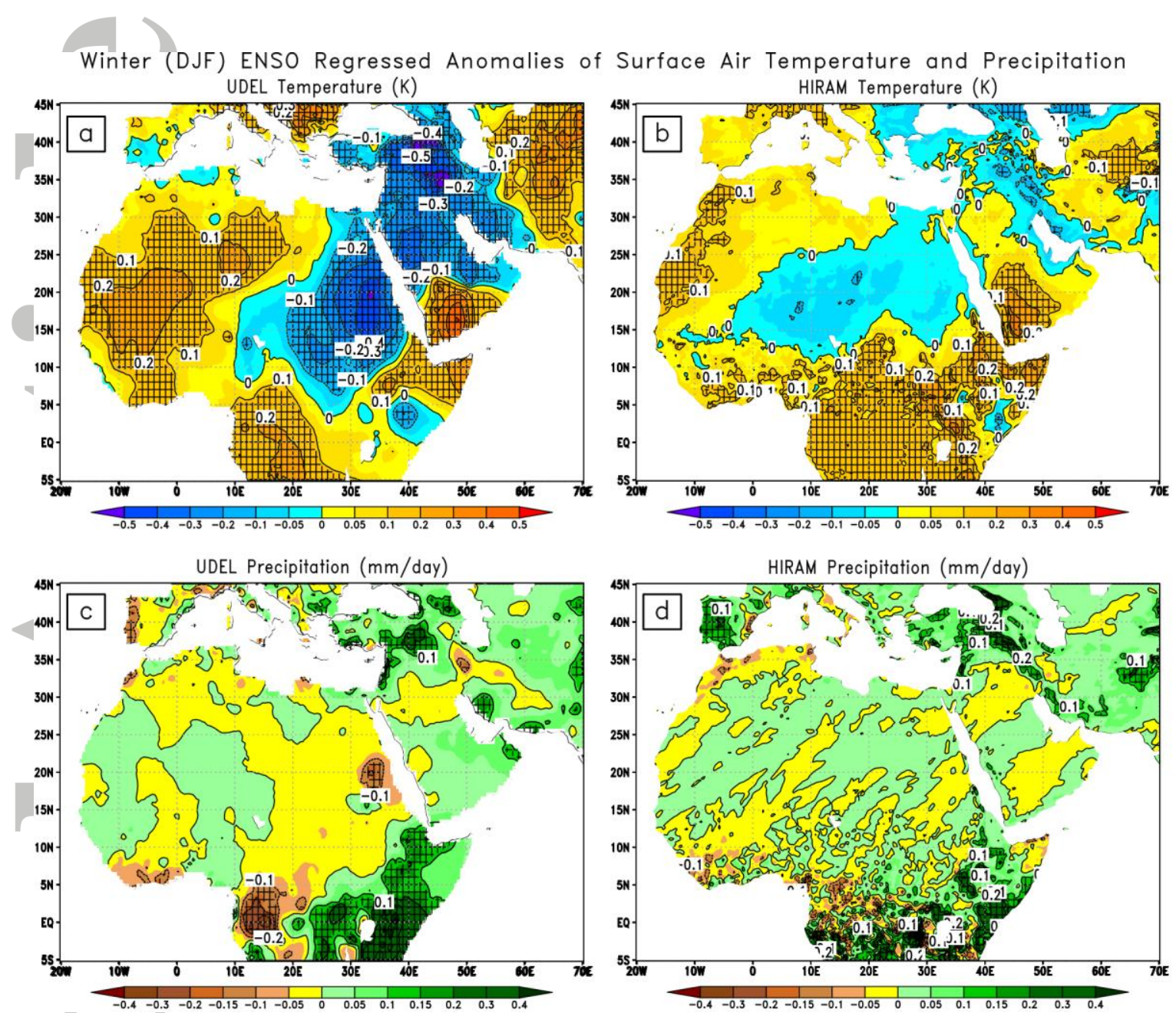

Figure 7: Winter (DJF) two-year ENSO-regressed anomalies of surface air temperature (K) and precipitation (mm/day) composited following the El Chichón and Pinatubo eruptions. The temperature composites are calculated using a) UDEL observations, b) HiRAM output, and precipitation composites using c) UDEL observations, d) HiRAM output. Hatching shows the statistically significant areas with at least $95 \%$ confidence level. 
Winter (DJF) NAO Regressed Anomalies of Surface Air Temperature and Precipitation
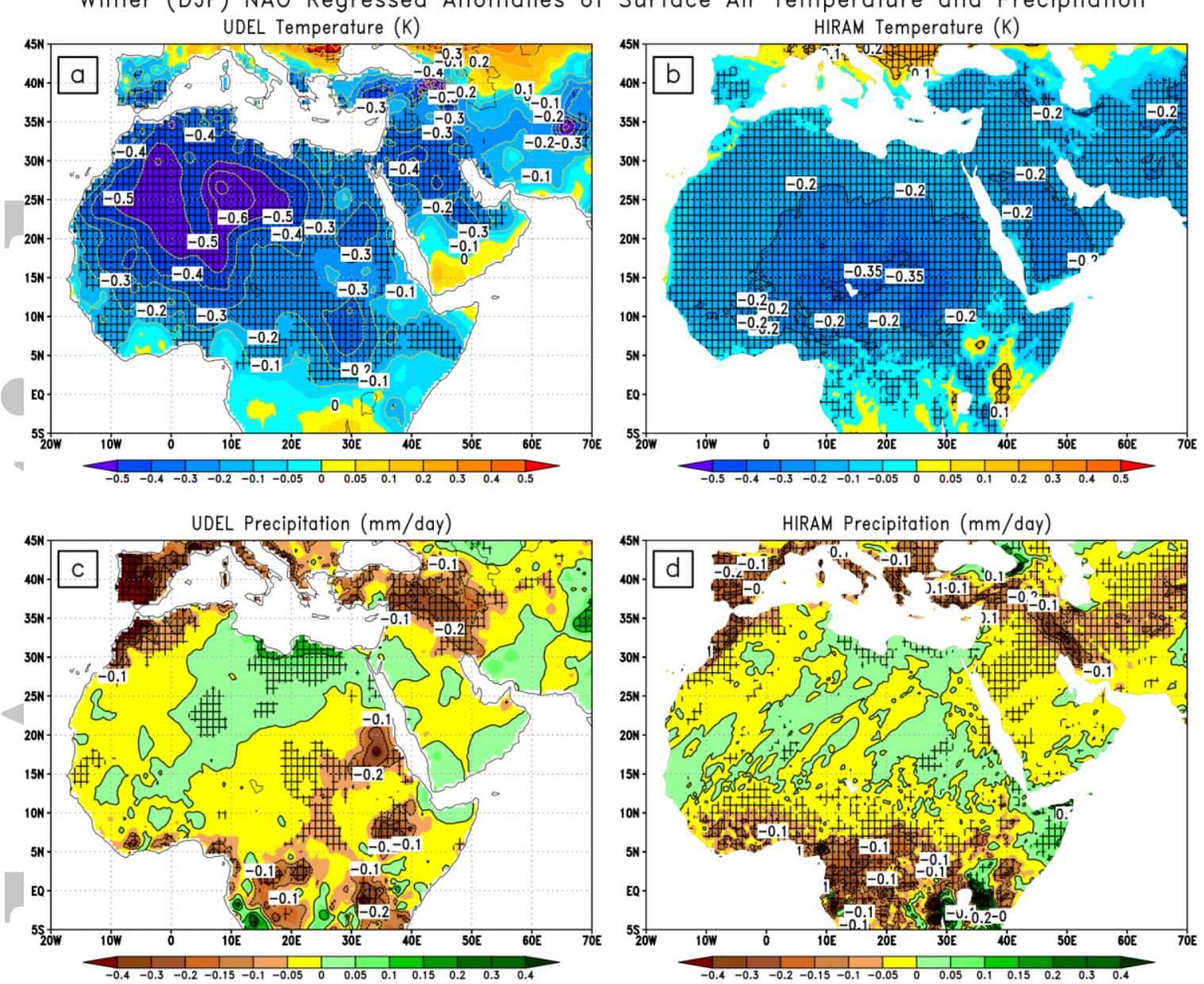

Figure 8: Winter (DJF) two-year NAO-regressed anomalies of surface air temperature (K) and precipitation (mm/day) composited following the El Chichón and Pinatubo eruptions. The temperature composites are calculated using a) UDEL observations, b) HiRAM output, and precipitation composites using c) UDEL observations, d) HiRAM output. Hatching shows the statistically significant areas with at least $95 \%$ confidence level. 

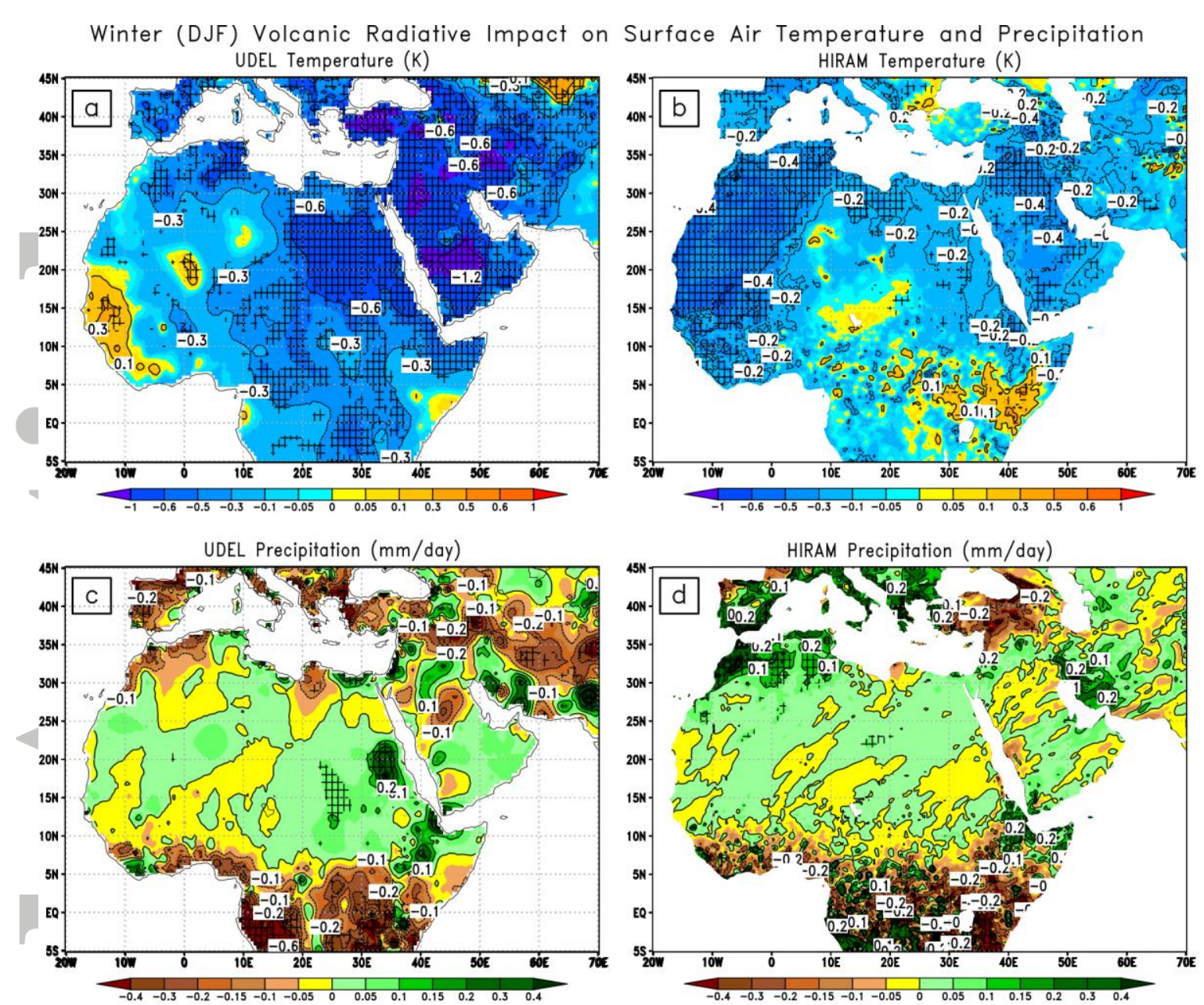

Figure 9: Winter (DJF) two-year volcanic residual anomalies (direct volcanic cooling) of surface air temperature (K) and precipitation (mm/day) composited following the El Chichón and Pinatubo eruptions. The temperature composites are calculated using a) UDEL observations, b) HiRAM output, and precipitation composites using c) UDEL observations, d) HiRAM output. Hatching shows the statistically significant areas with at least $95 \%$ confidence level.

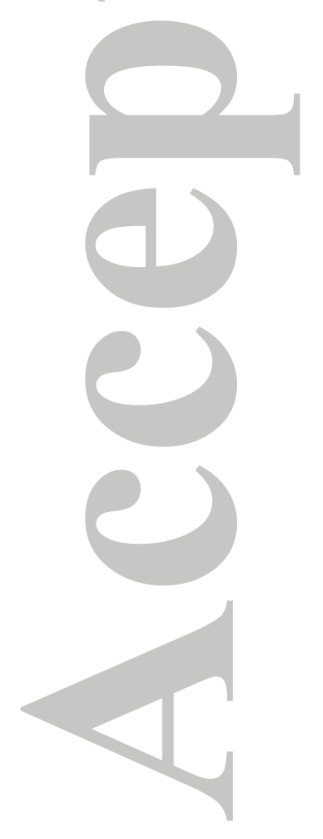


Summer (JJA) ENSO Regressed Anomalies of Surface Air Temperature and Precipitation
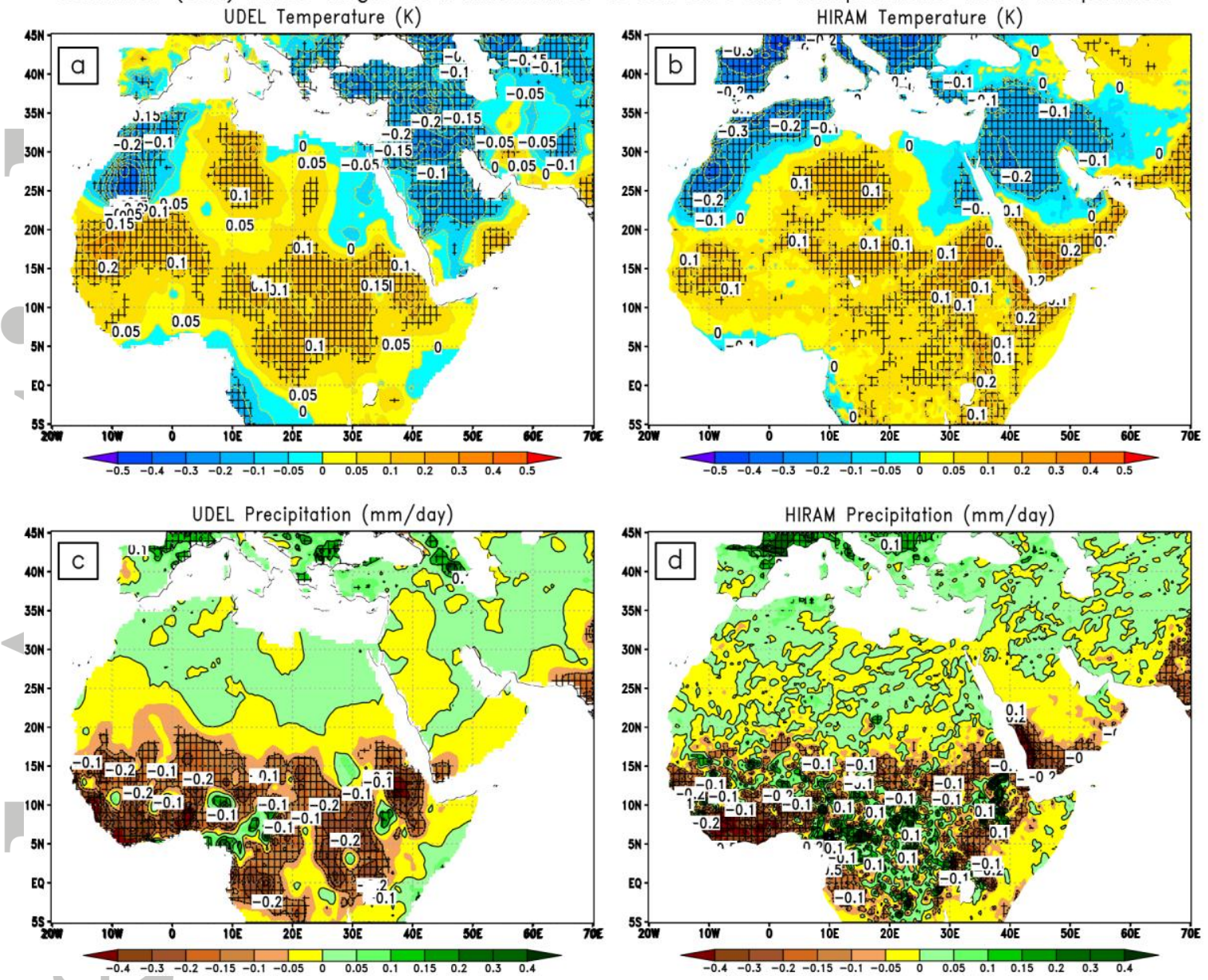

Figure 10: Summer (JJA) two-year ENSO-regressed anomalies of surface air temperature (K) and precipitation ( $\mathrm{mm} /$ day) composited following the El Chichón and Pinatubo eruptions. The temperature composites are calculated using a) UDEL observations, b) HiRAM output, and precipitation composites using c) UDEL observations, d) HiRAM output. Hatching shows the statistically significant areas with at least $95 \%$ confidence level. 
Summer (JJA) ISM Regressed Anomalies of Surface Air Temperature and Precipitation UDEL Temperature $(K)$
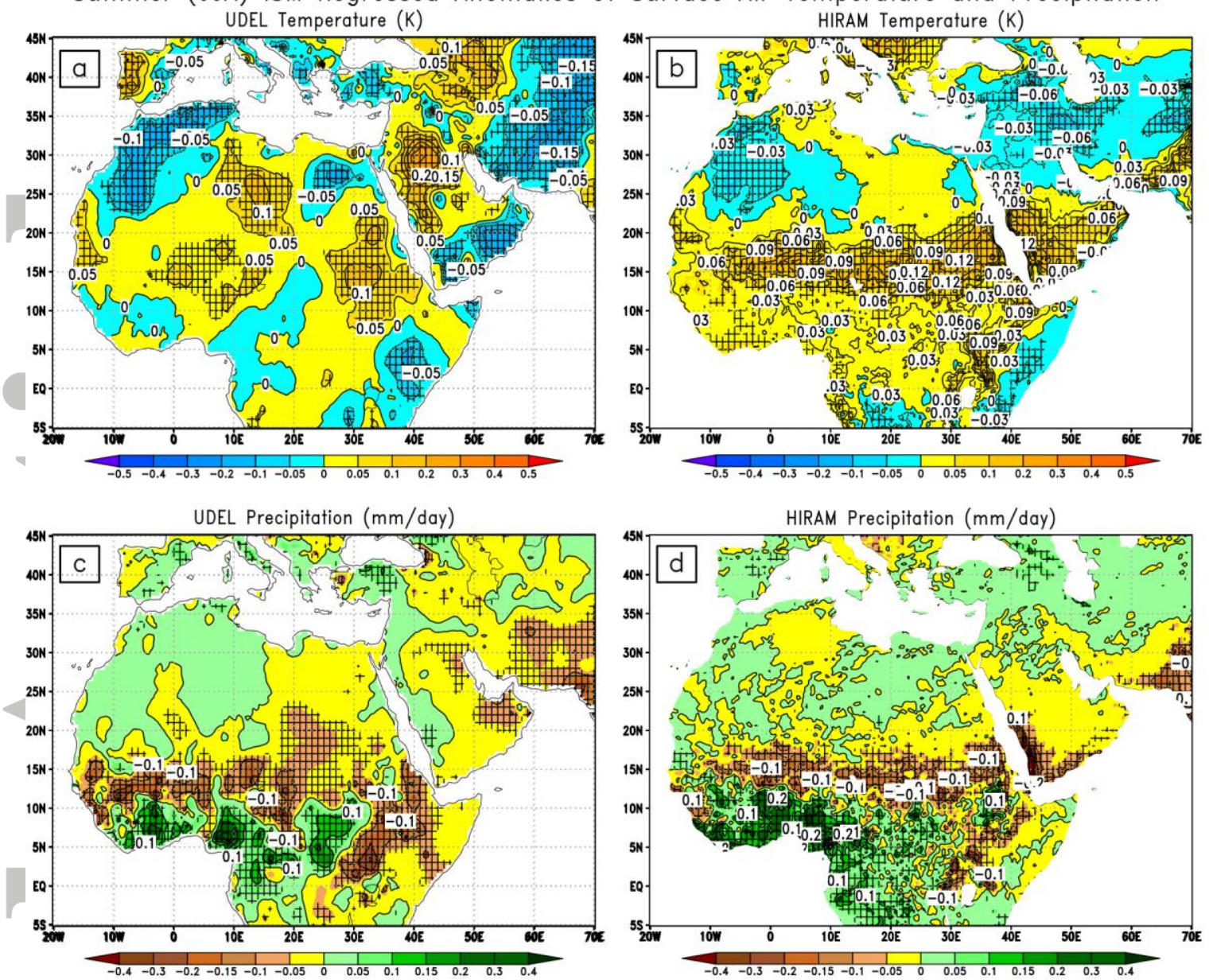

Figure 11: Summer (JJA) two-year ISM-regressed anomalies of surface air temperature (K) and precipitation $(\mathrm{mm} /$ day) composited following the El Chichón and Pinatubo eruptions. The temperature composites are calculated using a) UDEL observations, b) HiRAM output, and precipitation composites using c) UDEL observations, d) HiRAM output. Hatching shows the statistically significant areas with at least $95 \%$ confidence level.

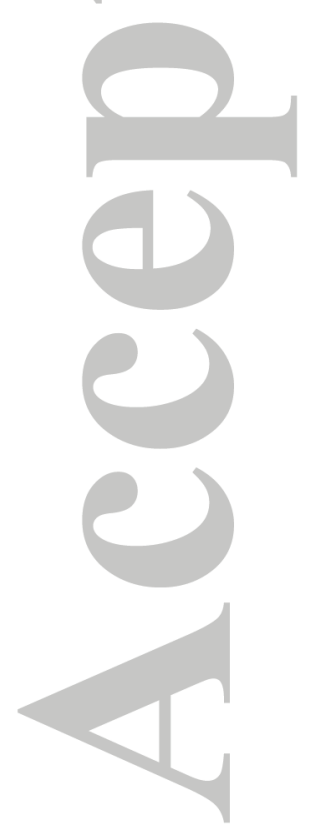


Summer (JJA) Volcanic Radiative Impact on Surface Air Temperature and Precipitation UDEL Temperature (K)
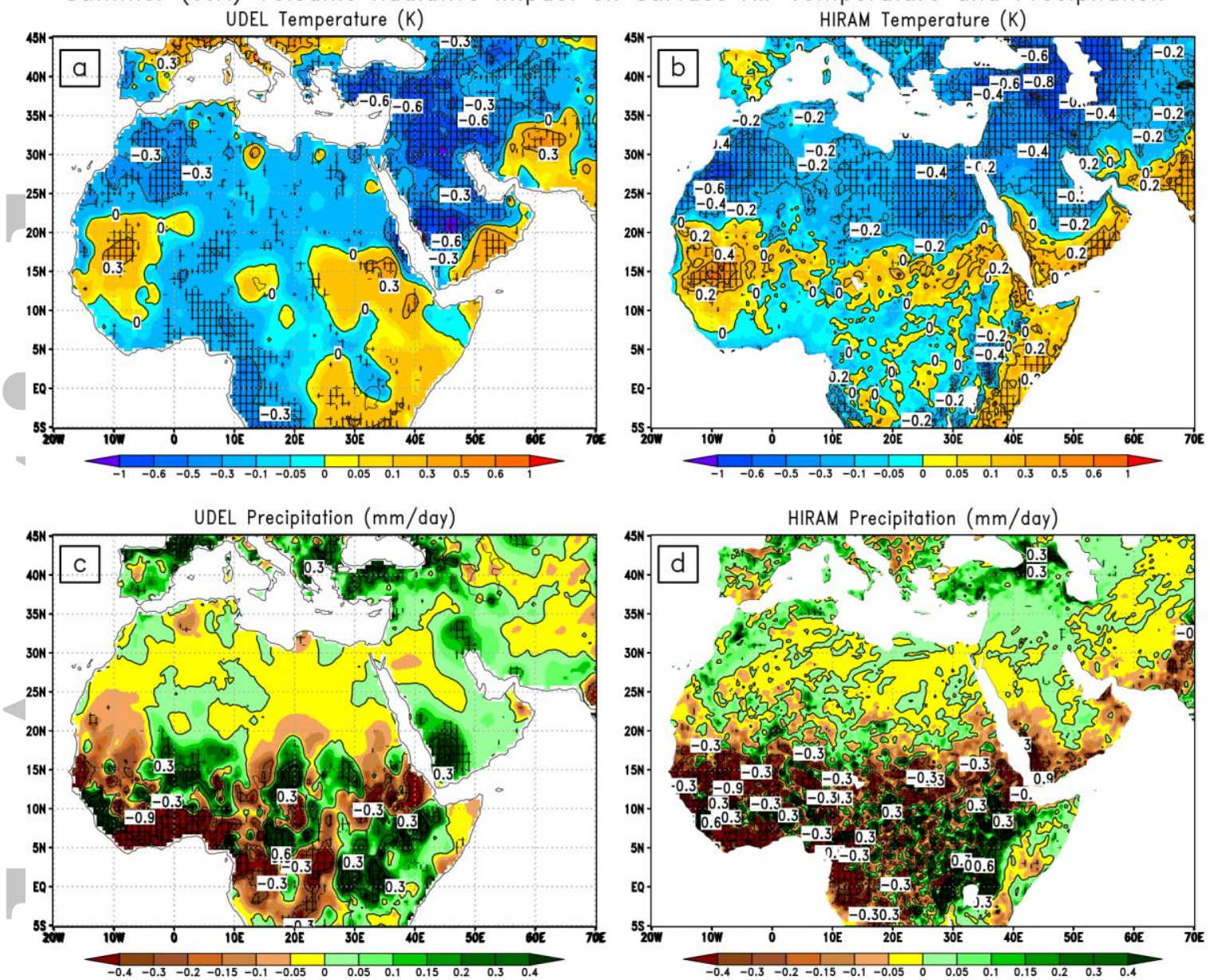

Figure 12: Summer (JJA) two-year volcanic residual anomalies (direct volcanic cooling) of surface air temperature $(\mathrm{K})$ and precipitation $(\mathrm{mm} /$ day) composited following the El Chichón and Pinatubo eruptions. The temperature composites are calculated using a) UDEL observations, b) HiRAM output, and precipitation composites - using c) UDEL observations, d) HiRAM output. Hatching shows the statistically significant areas with at least $95 \%$ confidence level.

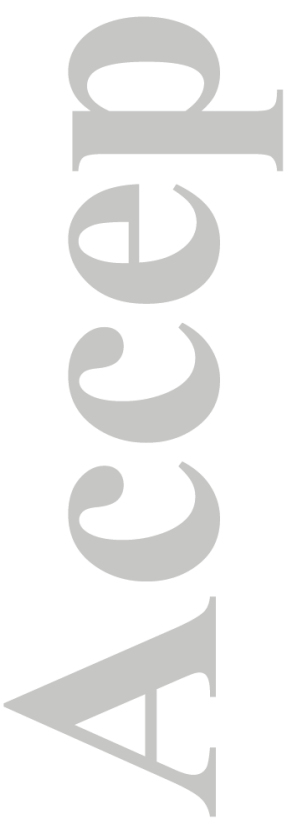


Winter (DJF) NAO Regressed Anomalies of Surface Air Temperature and Precipitation
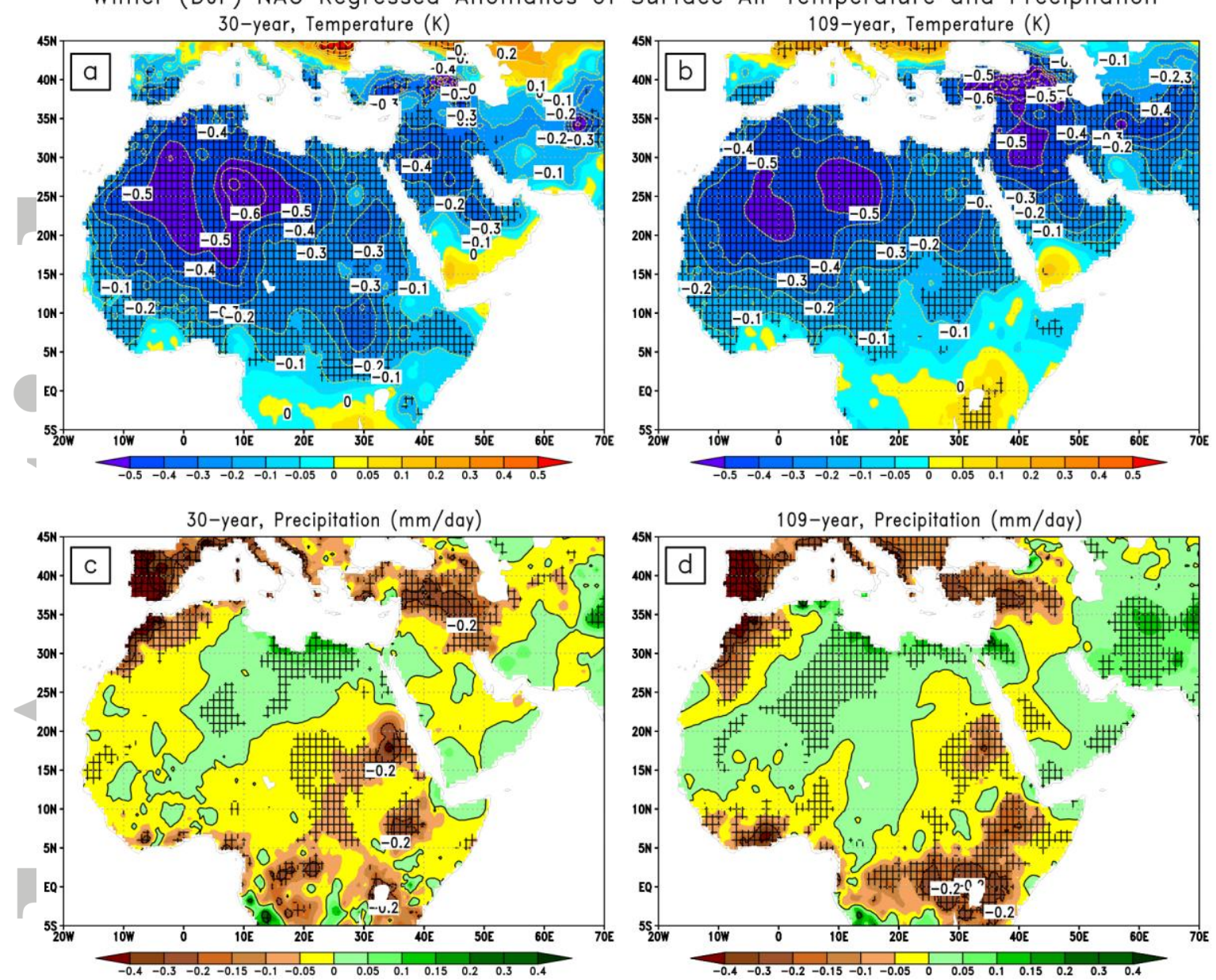

Figure 13: Winter (DJF) NAO-regressed anomalies of surface air temperature (K) and precipitation $(\mathrm{mm} /$ day) composited for two years following the El Chichón and Pinatubo eruptions. The temperature composites are calculated using a) UDEL 30-year period, b) UDEL 109-year period, and precipitation composites using c) UDEL 30-year period, d) UDEL 109-year period. Hatching shows the statistically significant areas with at least $95 \%$ confidence level.

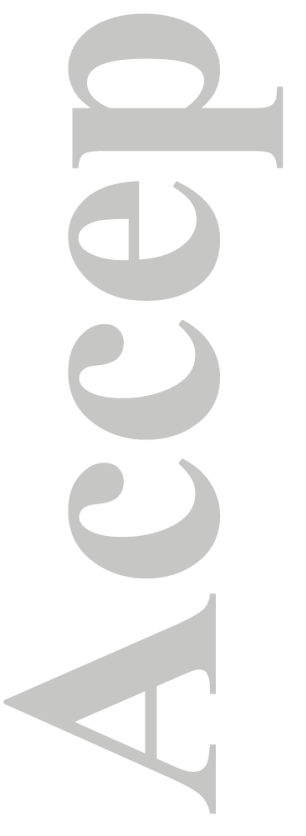


Winter (DJF) ENSO Regressed Anomalies of Surface Air Temperature and Precipitation
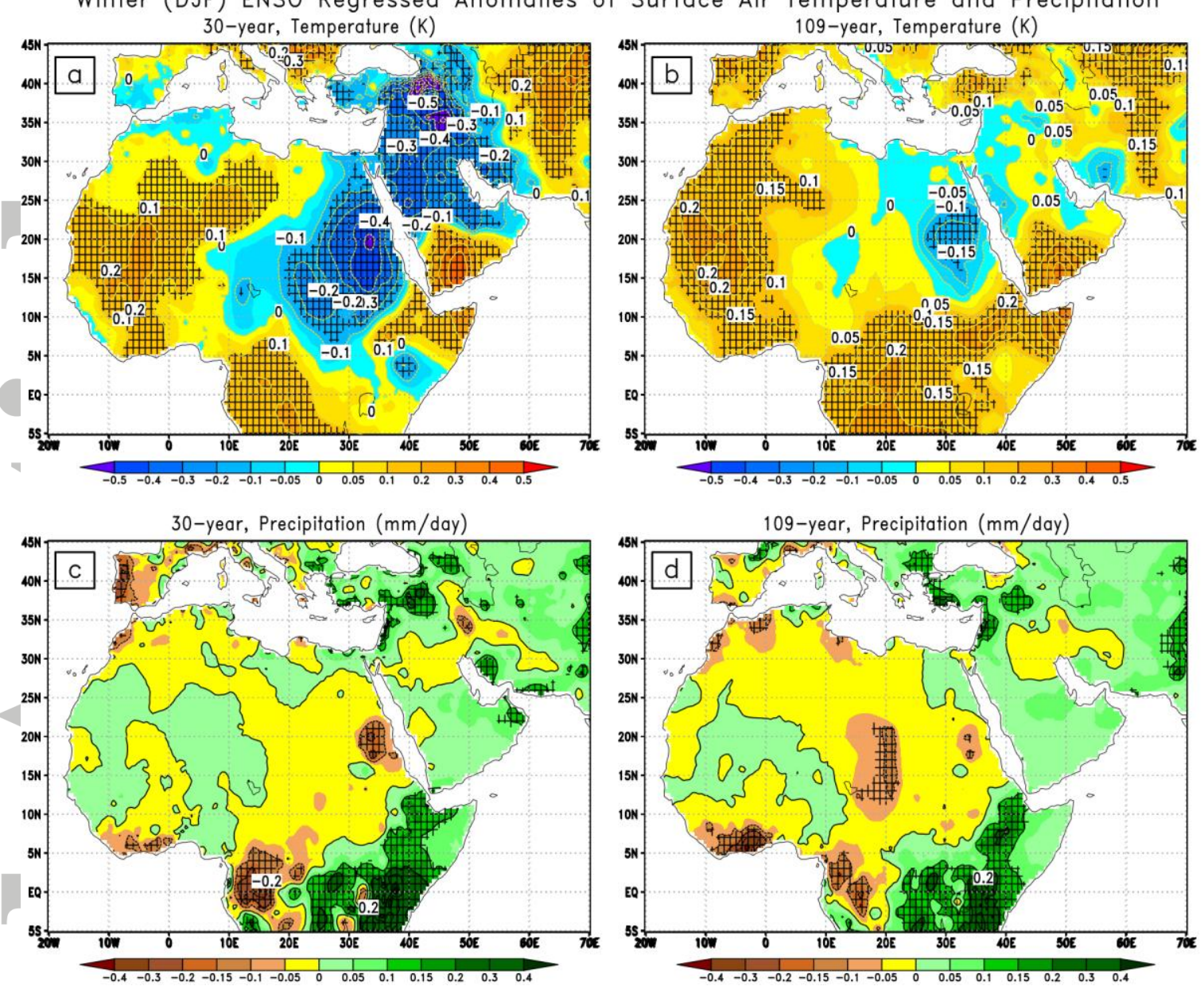

Figure 14: Winter (DJF) ENSO-regressed anomalies of surface air temperature (K) and precipitation $(\mathrm{mm} /$ day) composited for two years following the El Chichón and Pinatubo eruptions. The temperature composites are calculated using a) UDEL 30-year period, b) UDEL 109-year period, and precipitation composites using c) UDEL 30-year period, d) UDEL 109-year period. Hatching shows the statistically significant areas with at least $95 \%$ confidence level.

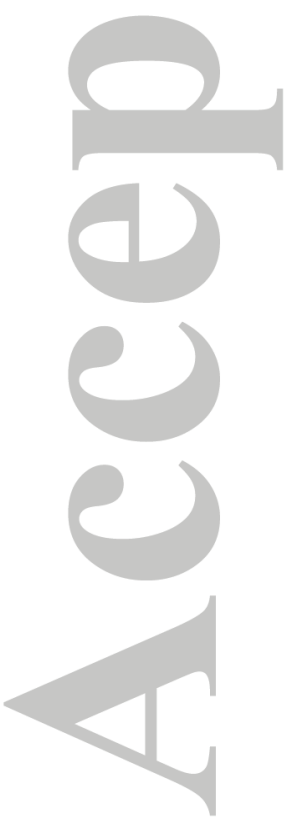


Summer (JJA) ENSO Regressed Anomalies of Surface Air Temperature and Precipitation 30-year, Temperature (K)
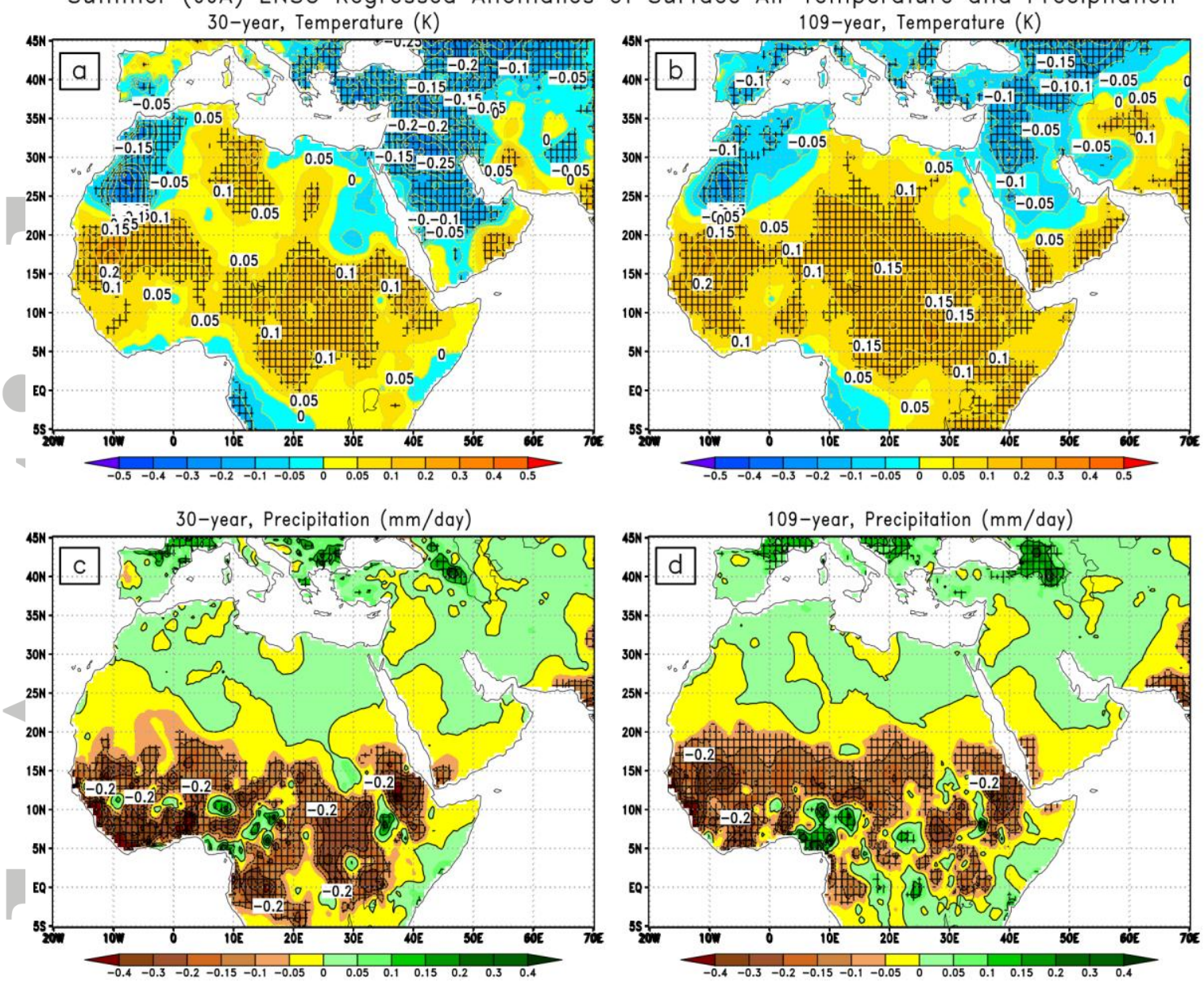

Figure 15: Summer (JJA) ENSO-regressed anomalies of surface air temperature (K) and precipitation ( $\mathrm{mm} / \mathrm{day})$ composited for two years following the El Chichón and Pinatubo eruptions. The temperature composites are calculated using a) UDEL 30-year period, b) UDEL 109-year period, and precipitation composites using c) UDEL 30-year period, d) UDEL 109-year period. Hatching shows the statistically significant areas with at least $95 \%$ confidence level.

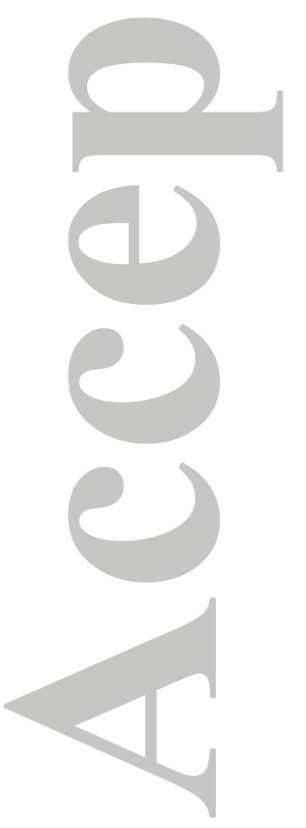


Summer (JJA) ISM Regressed Anomalies of Surface Air Temperature and Precipitation 30-year, Temperature $(\mathrm{K})$
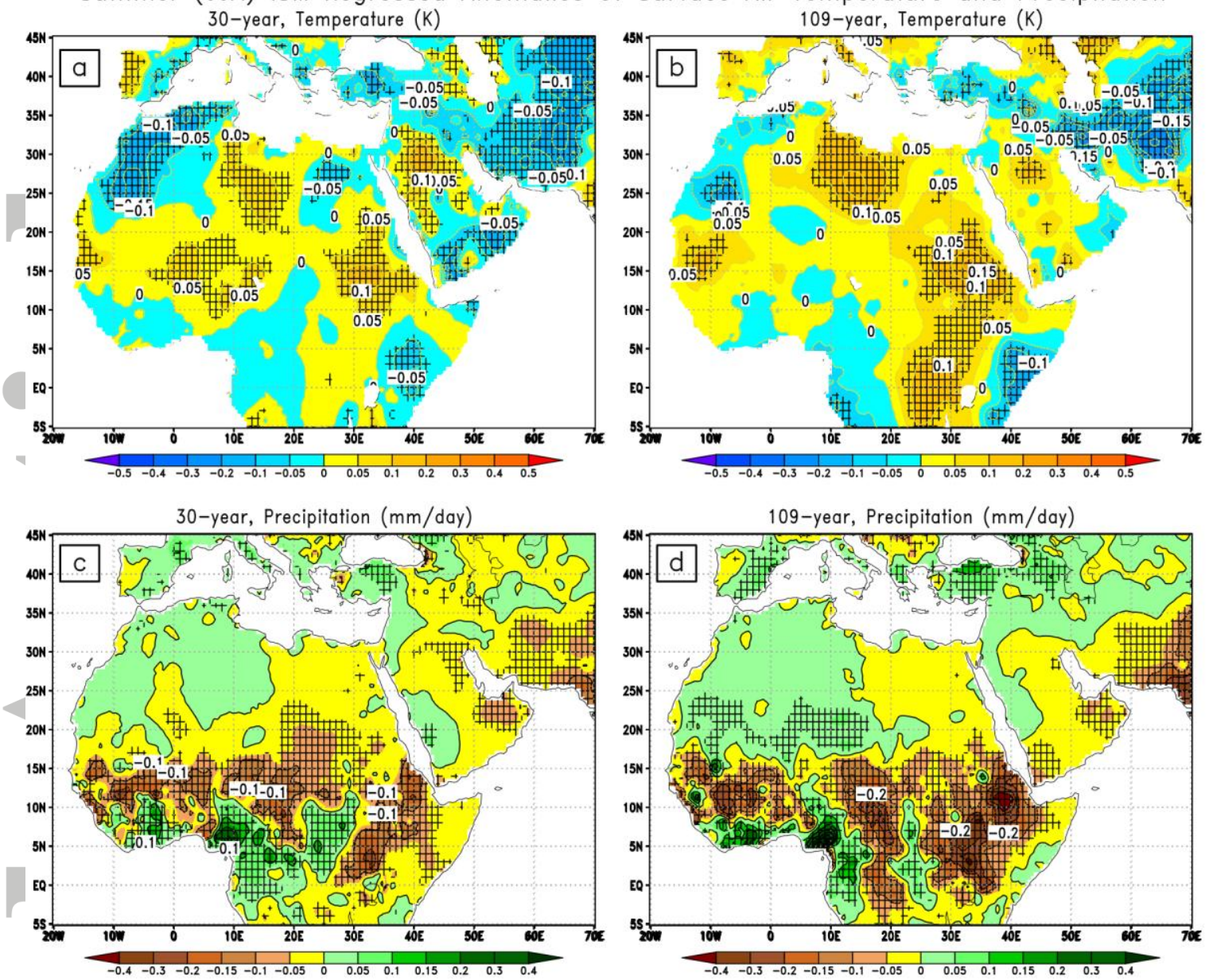

Figure 16: Summer (JJA) ISM-regressed anomalies of surface air temperature (K) and precipitation ( $\mathrm{mm} / \mathrm{day})$ composited for two years following the El Chichón and Pinatubo eruptions. The temperature composites are calculated using a) UDEL 30-year period, b) UDEL 109-year period, and precipitation composites using c) UDEL 30-year period, d) UDEL 109-year period. Hatching shows the statistically significant areas with at least $95 \%$ confidence level.

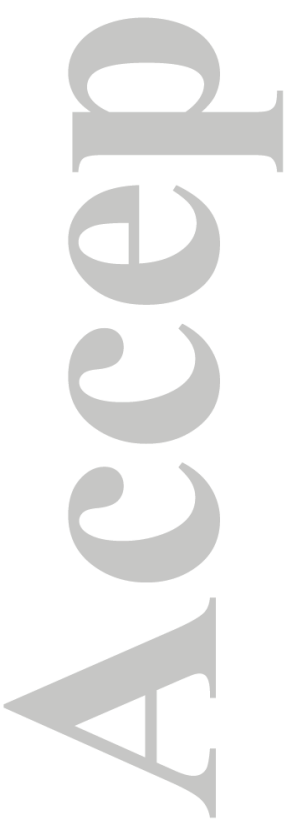



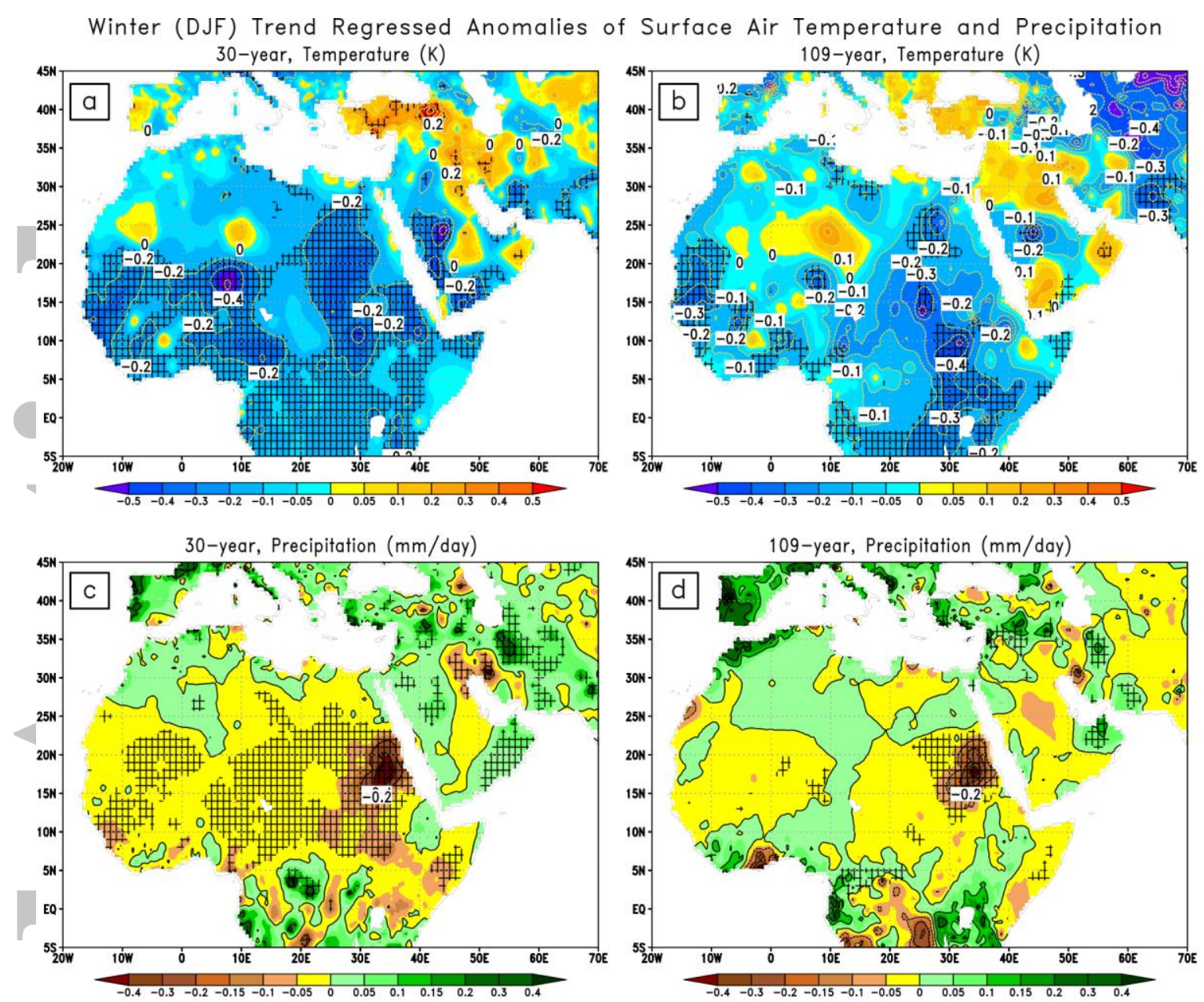

Figure 17: Winter (DJF) Trend-regressed anomalies of surface air temperature (K) and precipitation $(\mathrm{mm} /$ day) composited for two years following the El Chichón and Pinatubo eruptions. The temperature composites are calculated using a) UDEL 30-year period, b) UDEL 109-year period, and precipitation composites using c) UDEL 30-year period, d) UDEL 109-year period. Hatching shows the statistically significant areas with at least $95 \%$ confidence level.

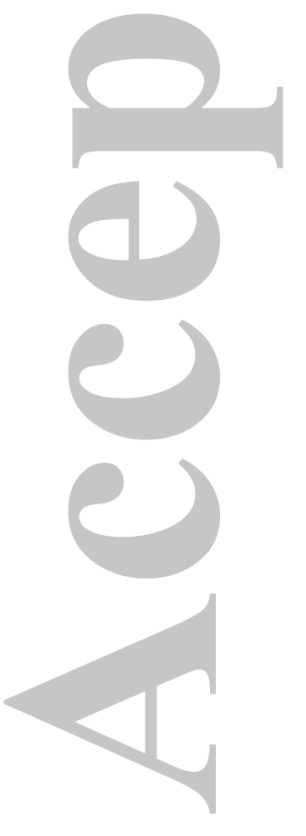



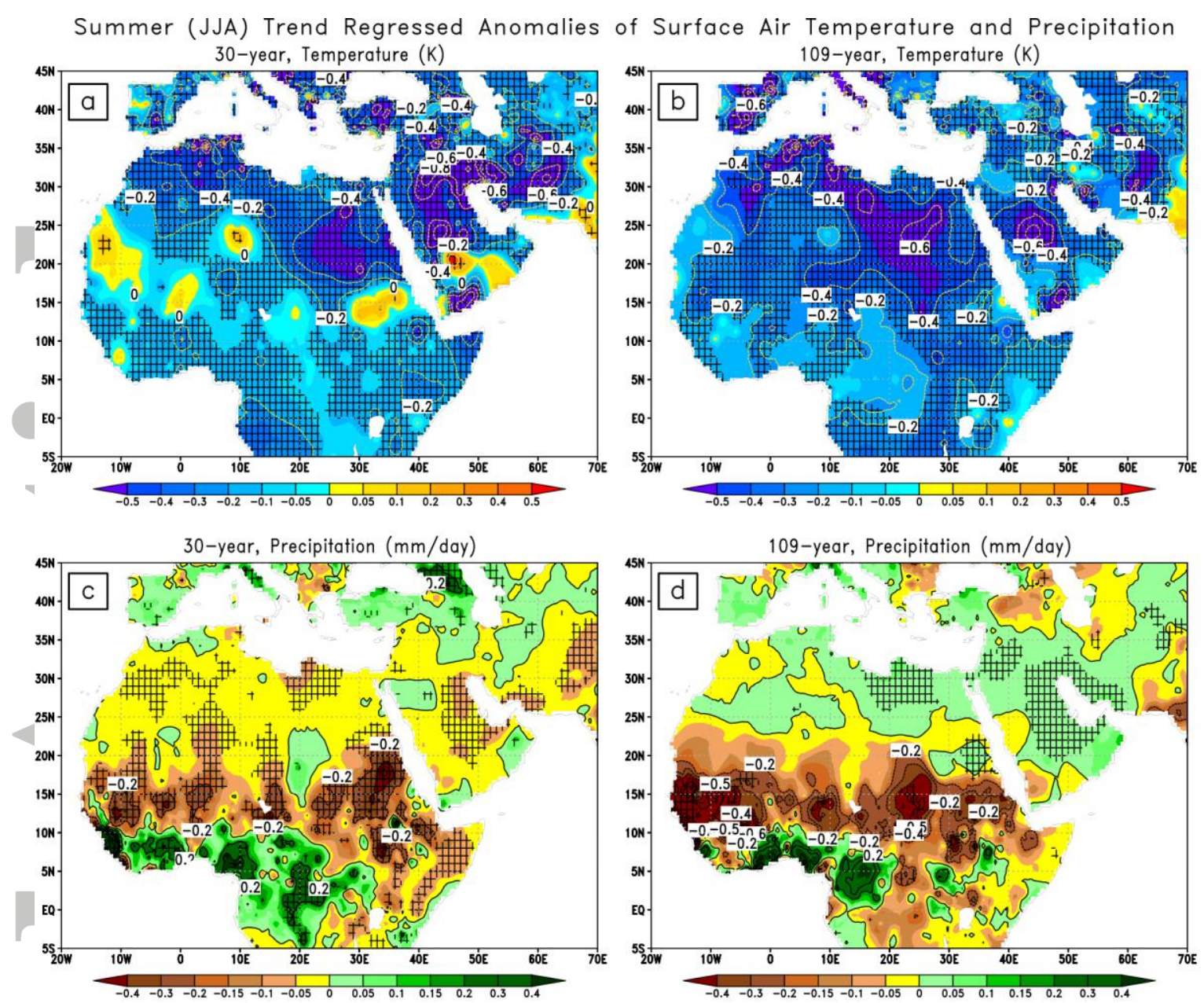

Figure 18: Summer (JJA) Trend-regressed anomalies of surface air temperature (K) and precipitation ( $\mathrm{mm} / \mathrm{day})$ composited for two years following the El Chichón and Pinatubo eruptions. The temperature composites are calculated using a) UDEL 30-year period, b) UDEL 109-year period, and precipitation composites using c) UDEL 30-year period, d) UDEL 109-year period. Hatching shows the statistically significant areas with at least $95 \%$ confidence level.

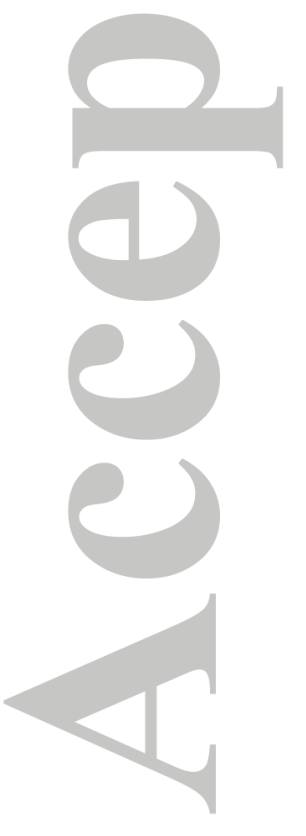

